\title{
Reprogramming of a subpopulation of human blood neutrophils by prolonged exposure to cytokines
}

\author{
Arpita Chakravarti ${ }^{1}$, Daniel Rusu ${ }^{1}$, Nicolas Flamand ${ }^{2}$, Pierre Borgeat ${ }^{1}$ and Patrice E Poubelle ${ }^{1}$
}

Essential cells of innate immunity, neutrophils are often considered to be a homogenous population of terminally differentiated cells. During inflammation, neutrophils are extravasated cells exposed to local factors that prolong their survival and activate their production of mediators implicated in disease progression. In this study, a phenotypically distinct subset of human neutrophils that appear after prolonged exposure to cytokines was characterized. Freshly isolated neutrophils from healthy donors were incubated with granulocyte-macrophage colony-stimulating factor, tumor necrosis factor- $\alpha$ and interleukin (IL)-4, three cytokines that are locally present in various inflammatory conditions. Eight to $17 \%$ of neutrophils survived beyond $72 \mathrm{~h}$. This subset of non-apoptotic neutrophils, as evaluated by three different markers, was enriched by discontinuous Percoll gradient centrifugation before studying their phenotype. These viable neutrophils showed neoexpression of HLA-DR, CD80 and CD49d. Compared with freshly isolated neutrophils, they responded differentially to second signals similar to formyl-methionyl-leucyl-phenylalanine with three- to four-fold increases in production of superoxide anions and leukotrienes. These cells augmented their phagocytic index by $141 \%$, increased their adhesion to human primary fibroblasts, but reduced their migration in response to chemotactic stimuli and decreased exocytosis of primary and secondary granules. In addition, they produced substantial amounts of IL-8, IL-1Ra and IL-1 $\beta$. This neutrophil subset had a unique profile of phosphorylation of intracellular signaling molecules. In conclusion, the present identification of a novel neutrophil phenotype highlights the reprogammable character of the neutrophil. This aspect is crucial for our understanding of its contribution to disease pathogenesis and host defense. Laboratory Investigation (2009) 89, 1084-1099; doi:10.1038/labinvest.2009.74; published online 27 July 2009

KEYWORDS: inflammation; innate; acquired immunity; survival

Neutrophils are the most abundant circulating leukocytes in human beings and are the first to migrate to inflammatory sites. They have a wide range of effector functions owing to preformed cytoplasmic and membrane proteins, enzymes and newly synthesized lipid and protein mediators that enable them to respond to diverse environmental triggers. ${ }^{1}$ Neutrophils are, thus, an essential arm of the immune system, mounting the initial inflammatory response and participating in host defense. Peripheral blood neutrophils are certainly the most studied type of neutrophils. However, during inflammation, these leukocytes leave the circulation and enter new habitats, the tissues in which they are exposed for extended periods to multiple factors such as cytokines, endogenous growth factors, bacterial products as well as multiple other local products. Indeed, the activity of infiltrating neutrophils has been intimately linked to disease evolution in a variety of clinical conditions. ${ }^{2-7}$ Thus, these cells contribute not only to acute inflammatory reactions, but also to the evolution of a variety of chronic inflammatory diseases.

Underlying the traditional definition of the neutrophil as a prototype effector of acute inflammation are two notions: that they are short lived, their lifespans being measured in hours, and that they have a predefined set of functions. As a corollary, they are most often considered all alike. Thus, functional and mechanistic studies on neutrophils generally treat them as a homogenous population of terminally differentiated cells. However, this concept is unsuited to several observations as evidence emerges that neutrophil lifespan is considerably prolonged in response to stimuli

\footnotetext{
${ }^{1}$ Department of Medicine, Centre de Recherche en Rhumatologie et Immunologie (CRRI), CRCHUL, Faculty of Medicine, Université Laval, Québec, Canada and ${ }^{2}$ Centre de Recherche de I'Hôpital Laval, Department of Medicine, Québec, Canada

Correspondence: Dr PE Poubelle, MD, DSc, Department of Medicine, Centre de Recherche en Rhumatologie et Immunologie (CRRI), CRCHUL, Faculty of Medicine, Laval University, 2705, Boulevard Laurier, \#T1-49, Québec, QC, Canada G1V 4 G2.
}

E-mail: Patrice.Poubelle@crchul.ulaval.ca

Received 29 December 2008; revised 1 May 2009; accepted 5 June 2009 
such as granulocyte-macrophage colony-stimulating factor (GM-CSF), tumor necrosis factor- $\alpha$ (TNF- $\alpha$ ), interleukins (ILs), interferons and bacterial products. ${ }^{8-12}$ Indeed, a percentage of neutrophils obtained from lungs in inflammatory lung injury and from synovial fluids of patients with rheumatoid arthritis have been seen to persist for days. ${ }^{13-16}$ The dogma that neutrophils are all alike is countered by a growing number of studies showing the functional heterogeneity of neutrophils. Neutrophil subsets have been demarcated with identifiable characteristics in terms, for example, of their expression of formyl-methionyl-leucylphenylalanine (fMLP) receptors. ${ }^{17}$ Recently, $5-8 \%$ of human neutrophils have been shown to express functional T-cell receptor. ${ }^{18}$ In addition to normal neutrophils, two subsets of mouse neutrophils exhibiting different susceptibilities to methicillin-resistant Staphylococcus aureus have also been identified that have different cytokine and chemokine production, effect on macrophage activation, Toll-like receptors and surface antigen expression. ${ }^{19}$

In this work, we propose to extend the concept of neutrophil subsets to inflammatory situations in which neutrophils are major participants. In addition to the heterogeneity in circulating neutrophils evoked in earlier studies, specific inflammatory conditions can also favor the emergence of neutrophil subpopulations with distinct phenotypes. After a 72-h incubation of normal human blood neutrophils with a combination of GM-CSF, TNF- $\alpha$ and IL-4, mediators known to be present in inflammatory conditions such as early arthritis, allergic asthma and skin pustulosis, and to influence neutrophil survival and functions, ${ }^{7,8,20-23}$ we isolated and characterized a subset of neutrophils with a functional profile that is markedly different from that of freshly isolated neutrophils. Constituting $8-17 \%$ of the global neutrophil populations exposed to the cytokines, these cells have substantially increased lifespan persisting beyond $72 \mathrm{~h}$. They have a unique inflammatory profile seen in the pattern of surface marker expression, production of superoxide anions $\left(\mathrm{O}_{2}^{-}\right)$, phagocytosis, leukotriene biosynthesis, chemotactic responses and degranulation. In addition, this subset produces substantial amounts of cytokines, such as IL-1, IL-1 receptor antagonist (IL-1Ra) and IL-8, and interacts strongly with resident stromal cells. We conclude that certain inflammatory conditions can induce a phenotypic 'switch' in the circulating neutrophil toward a resident neutrophil with different and new functions.

\section{MATERIALS AND METHODS Reagents}

Dextran T-500 and Percoll were obtained from GE Healthcare, Canada. Ficoll-Paque, RPMI 1640 and fetal bovine serum (FBS) were obtained from Wisent (St-Bruno, QC, Canada). Human recombinant GM-CSF, IL-4 and TNF- $\alpha$ were obtained from Peprotech (Rocky Hill, NJ, USA). FITC-conjugated annexin- $\mathrm{V}$ and propidium iodide (PI) were from Biovision (Mountainview, CA, USA). The fMLP, phorbol 12-myristate 13-acetate (PMA), A23187 calcium ionophore, pyruvate solution, human lactoferrin (LF), antihuman LF antibody and O-dianiside hydrochloride were obtained from Sigma Chemical Co. (St-Louis, MO, USA). FITC-conjugated zymosan particles, wheat germ agglutinin (WGA) lectin and 4',6-diamidino-2-phenylindole (DAPI) were from Molecular Probes (Invitrogen Canada Inc. Burlington, ONT, Canada). Hema-Quick II was obtained from Biochemical Sciences (Swedesboro, NJ, USA). Chemotaxis plates (96 wells) were purchased from Neuroprobes (Gaithersburg, MD, USA). Cytochrome $c$ was from MP Biomedicals (Solon, OH, USA). Anti-human HLA-DR, CD80, CD86, CD11b, CD18 antibodies (Ab) and IgG1, IgG2a, IgG2b were all purchased from BD Biosciences Pharmingen (San Diego, CA, USA) and peroxidase-conjugated anti-rabbit $\mathrm{Ab}$ was from Jackson ImmunoResearch (West Grove, PA, USA). Apostat intracellular caspase detection kit (FITC-VD-FMK), EIA kit for IL-1Ra (biotinylated secondary goat anti-human IL-1Ra Ab: DY280, \#1144097) and Proteome Profiler: Human Phospho-MAP Kinase Array Kit were obtained from R\&D Systems (Minneapolis, MN, USA). EIA kits for IL-8 (biotinylated secondary mouse IgG1 anti-human IL-8 Ab: CHC1303, \#061901) and IL-1 $\beta$ (583311, \#189338) were purchased from Biosource international (Camarillo, CA, USA) and Cayman Chemicals (Ann Arbor, MI, USA), respectively.

\section{Preparation of Human Leukocytes}

The institutional review board of the Universite Laval (Québec, QC, Canada) approved this study and healthy adult volunteers signed a consent form. Peripheral blood neutrophils were prepared as described earlier in sterile conditions at room temperature. ${ }^{24}$ Briefly, human venous blood collected on citrate phosphate dextrose adenine anticoagulant solution was centrifuged $(250 \mathrm{~g}, 15 \mathrm{~min})$ and the platelet-rich plasma was removed. After dextran sedimentation of the erythrocytes, neutrophils were purified by centrifugation over a Ficoll-Paque cushion $(450 \mathrm{~g}, 20 \mathrm{~min})$. Neutrophils were collected at the bottom and contaminating erythrocytes were eliminated by hypotonic lysis (15 s). After two washes, neutrophils were counted and resuspended in RPMI $1640+10 \%$ decomplemented FBS with or without $500 \mathrm{pM}$ GM-CSF $+10 \mathrm{ng} / \mathrm{ml}$ IL- $4+10 \mathrm{ng} / \mathrm{ml}$ TNF- $\alpha$. Cell viability was routinely assessed by trypan blue dye exclusion test and was $>99 \%$. Neutrophils were incubated at $10^{7}$ cells/ $\mathrm{ml}$, in 12 -well plates $(2 \mathrm{ml} /$ well $)$ at $37^{\circ} \mathrm{C}, 5 \% \mathrm{CO}_{2}$ for 3 days.

After 3 days of incubation, viable neutrophils were isolated from the incubated neutrophils by discontinuous Percoll density gradient centrifugation, as described earlier with slight modifications. ${ }^{25}$ Briefly, neutrophil suspensions were added to discontinuous Percoll gradients created by gently layering equal volumes of 31,42 and $51 \%$ of a standard isotonic Percoll solution (90\% Percoll $+10 \% 10 \times$ phosphate-buffered saline (PBS)) in diluent (PBS) and centrifuged at $610 \mathrm{~g}$ for $28 \mathrm{~min}$ at $4^{\circ} \mathrm{C}$. The $0 / 31$ and $42 / 51 \%$ Percoll 
interfaces contained the majority of necrotic, late and early apoptotic cells ( $>90 \%$ were annexin-V-positive cells or incorporated PI), whereas the viable cells were collected at the bottom. Percoll-enriched cells were washed thrice in excess of PBS and were used for subsequent tests after assessment of cell viability by annexin/PI, as described below.

Suspensions of peripheral blood mononuclear leukocytes (PBMLs) were prepared as described earlier. ${ }^{24}$ PBMLs were enriched in their monocyte fraction by adherence on plastic petri dishes $\left(5 \times 10^{6} \mathrm{cells} / \mathrm{ml}, 37^{\circ} \mathrm{C}, 90 \mathrm{~min}\right)$. The non-adherent fraction was removed by repeated washes, the adherent monocyte fraction was treated with accutase, counted and incubated with the combination of cytokines as above. Purity was $90-92 \%$ monocytes, as assessed by Wright-Giemsa and non-specific esterase staining.

Human blood eosinophils from healthy volunteers were purified as described earlier with slight modifications. ${ }^{26}$ After dextran sedimentation and centrifugation on Ficoll-Paque cushions, eosinophils were isolated from the granulocyte pellet by negative selection using an anti-CD16 monoclonal $\mathrm{Ab}$ conjugated with magnetic beads and the magnetic $\mathrm{Ab}$ cellsorting apparatus (Miltenyi Biotec, Bergisch-Gladbach, Germany). Purity (Hema-Quick staining) and viability (trypan blue exclusion) of the eosinophil preparations were always $>98.5$ and $99 \%$, respectively.

\section{Microscopy}

Cells were spun onto slides, air dried for $5 \mathrm{~min}$, stained with Hema-Quick II solution and examined by light microscopy (magnification $\times 100)$. Neutrophils were resuspended in $50 \mu \mathrm{l}$ PBS, placed on coverslips, air dried, fixed in $4 \%$ paraformaldehyde $\mathrm{pH} 7.4$ for $15 \mathrm{~min}$, washed two times, labeled with OG488-WGA-lectin $(496 / 524 \mathrm{~nm})$ and DNAbinding nuclear marker DAPI $(358 / 461 \mathrm{~nm})$ before epifluorescence microscopy. Images were visualized using Olympus BX-41TF microscope using the appropriate filter sets for the fluorochromes and analyzed by the Imagepro software. For transmission electron microscopy, cells were fixed in 4\% paraformaldehyde and $2.5 \%$ glutaraldehyde $(100 \mathrm{mM}$ sodium cacodylate buffer, $\mathrm{pH} 7.3$ ) for $24 \mathrm{~h}$ at $4{ }^{\circ} \mathrm{C}$. After postfixation in $1 \% \mathrm{OsO}_{4}$ (in the same buffer) for $90 \mathrm{~min}$ at $20^{\circ} \mathrm{C}$, the samples were dehydrated in an ethanol/propylene oxide series and embedded in Epon. Ultrathin sections of $80 \mathrm{~nm}$ were produced with a Reichert-Jung Ultramicrotome (Vienna, Austria). These sections were then transferred to a 200-mesh nickel/Formvar grid and stained with $3 \%$ uranyl acetate/lead citrate. Samples were examined in a JEM-1230 microscope (Jeol, Tokyo, Japan) at $80 \mathrm{kV}$.

\section{Analysis of Viability}

Neutrophil viability was evaluated by the lactate dehydrogenase (LDH) release assay. ${ }^{27}$ After incubations, suspensions of neutrophils were centrifuged. Supernatants and cell pellets were collected separately. Cells were lysed with Triton X-100, and $1.25 \mathrm{ml}$ of substrate solution $(0.14 \mathrm{mg} / \mathrm{ml} \mathrm{NADH}$ in
$0.1 \mathrm{M}$ sodium phosphate buffer, $\mathrm{pH}$ 7.35) together with $50 \mu \mathrm{l}$ of pyruvate solution were added to $50 \mu$ l of lysed cells or supernatants; samples were analyzed by colorimetry at $340 \mathrm{~nm}$. The results were expressed as percentages of the ratio of optical density values measured in supernatants by total optical density values (cells plus supernatant).

Neutrophils simultaneously labeled with FITC-conjugated annexin-V and PI were also evaluated for viability by flowcytometry. Briefly, cells were collected by centrifugation and resuspended in $500 \mu \mathrm{l}$ of binding buffer $1 \mathrm{X}$ supplied with the kit; $5 \mu \mathrm{l}$ of FITC-labeled annexin-V and PI were then added and the cells were subsequently incubated for $5 \mathrm{~min}$ at room temperature in the dark. Ten thousand cells were counted and cell death was calculated as the number of cells stained by annexin-V or PI.

Apoptosis of neutrophils was also estimated by intracellular caspase activity, as determined by FITC-conjugated VD-FMK. Briefly, $10 \mu \mathrm{l}$ Apostat reagent was added to 1 million cells in $1 \mathrm{ml}$. After incubation at $37^{\circ} \mathrm{C}$ for $30 \mathrm{~min}$, cells were harvested, washed and resuspended in $500 \mu \mathrm{l}$ of PBS for analysis by flowcytometry.

\section{Analysis by Flowcytometry}

For immunofluoresence staining, $100 \mu \mathrm{l}$ of cell suspensions $\left(10^{7}\right.$ cells $\left./ \mathrm{ml}\right)$ were incubated for $30 \mathrm{~min}$ at $4^{\circ} \mathrm{C}$ with FITC-, $\mathrm{PE}$-conjugated or unconjugated mAbs. For analysis using unconjugated mAbs, FITC-conjugated $\mathrm{F}\left(\mathrm{ab}^{\prime}\right)_{2}$ fragments of goat anti-mouse immunoglobulin antibodies were used as a second step reagent. The analysis was performed by flowcytometry (EPICS-XL Beckman Coulter, Miami, FL, USA). Ten thousand events were counted and cell debris was excluded based on forward and side-light scatters. For cell cycle analysis, cell suspensions $\left(2 \times 10^{6}\right.$ cells $\left./ \mathrm{ml}\right)$ were added dropwise to an equal volume of ice-cold absolute ethanol. After $24 \mathrm{~h}$, cells were washed with $3 \mathrm{ml}$ of cold buffer and stained with DNA-intercalating dye PI $(40 \mu \mathrm{g} / \mathrm{ml}), 30 \mathrm{~min}$ at room temperature, in the presence of RNAase $(200 \mu \mathrm{g} / \mathrm{ml})$. DNA content was subsequently assessed by flowcytometry.

\section{Evaluation of Neutrophil Functions Production of $\mathrm{O}_{2}^{-}$}

$\mathrm{O}_{2}^{-}$production was assessed by the superoxide dismutasesensitive reduction of cytochrome $c^{28}$ Neutrophils were suspended in Hanks' balanced salt solution (HBSS) containing calcium $(1.6 \mathrm{mM})$. Cell suspensions $\left(1 \times 10^{6}\right.$ cells $\left./ \mathrm{ml}\right)$ were then preincubated with $125 \mu \mathrm{g} / \mathrm{ml}$ of freshly prepared cytochrome $c$ in HBSS and tubes were placed in a shaking water bath at $37^{\circ} \mathrm{C}$ for $5 \mathrm{~min}$ in the presence of fMLP, PMA or A23187 calcium ionophore $\left(10^{-7} \mathrm{M}\right.$ final concentration). The reactions were terminated by rapidly transferring the tubes to an ice-cold water bath and adding superoxide dismutase (final concentration, $62.5 \mu \mathrm{g} / \mathrm{ml}$ ), followed by centrifugation $\left(1000 \mathrm{~g}, 30 \mathrm{~min}, 4^{\circ} \mathrm{C}\right)$. Supernatants were immediately transferred to cuvettes for measurement of reduced cytochrome $c$ absorbance at $550 \mathrm{~nm}$ with a Beckman DU 
spectrophotometer. The change in optical density was converted to nanomoles of $\mathrm{O}_{2}^{-}$released into supernatants using the extinction coefficient $E_{550}=21 \times 10^{3} / \mathrm{M} / \mathrm{cm}$.

\section{Chemotaxis}

Neutrophil migration assay was performed using disposable 96-well chemotaxis chambers with $3 \mu \mathrm{m}$ pore membrane. Cells were exposed to $5 \mu \mathrm{g} / \mathrm{ml}$ of the fluorescent probe calcein-AM at $37^{\circ} \mathrm{C}$ for $30 \mathrm{~min}$. Calcein-AM-loaded neutrophils were washed and resuspended in complete medium $\left(3 \times 10^{6}\right.$ cells $\left./ \mathrm{ml}\right)$. The wells of the chemotaxis plates were filled in duplicate with a control solution (PBS), fMLP, $\mathrm{LTB}_{4}$ or IL- $8\left(10^{-10}-10^{-6} \mathrm{~mol} / \mathrm{l}\right)$. The polycarbonate membrane was placed over the wells and 60000 neutrophils/chamber were added on top of the membrane. Cells were allowed to migrate for $60 \mathrm{~min}$ at $37^{\circ} \mathrm{C}$. Cells that did not migrate through the filter were removed gently by scraping. The filter was analyzed using a fluorescence reader (Bio-Tek Instruments) at the excitation and emission wavelengths of 485 and $530 \mathrm{~nm}$, respectively. Fluorescence intensities were proportional to the number of cells that crossed the filter.

\section{Release of myeloperoxidase and $L F$}

Myeloperoxidase (MPO), a marker for primary granules, was measured by the method of Bradley with slight modifications. ${ }^{29}$ Five (5) million neutrophils/ml were stimulated with vehicle, fMLP, PMA or A23187 as above. The reactions were stopped by transferring the tubes to an ice-cold water bath. Supernatants and cells were collected in separate tubes after a quick centrifugation. Cells were lysed in a $50-\mathrm{mM}$ phosphate buffer (pH6) containing $0.5 \%$ hexadecyltrimetylammonium bromide, and adjusted to a final volume of $1 \mathrm{ml}$. One hundred (100) $\mu \mathrm{l}$ of supernatants or cells were added to $2.4 \mathrm{ml}$ of a mixture of potassium phosphate buffer, $0.2 \mathrm{mg} / \mathrm{ml}$ of O-dianiside hydrochloride and $500 \mu \mathrm{l}$ of $0.003 \% \mathrm{H}_{2} \mathrm{O}_{2}$. Absorbance was measured at $460 \mathrm{~nm}$. MPO contents were calculated using an MPO calibration curve created with known dilutions of human MPO. The results are expressed as percentage of MPO released to total MPO.

Release of LF, a marker for specific granules, was measured by ELISA. ${ }^{30}$ Briefly, $100000 \mathrm{cells} / \mathrm{ml}$ were stimulated with vehicle, fMLP, PMA or A23187 (at a final concentration of $10^{-7} \mathrm{M}$ each) for $5 \mathrm{~min}$ at $37^{\circ} \mathrm{C}$ in the presence or absence of $1 \mu \mathrm{g} / \mathrm{ml}$ cytochalasin $\mathrm{B}$, an actin depolymerizing agent shown to amplify granule exocytosis. Supernatants were diluted 10 - and 100 -fold in $50 \mathrm{mM} \mathrm{CO} / \mathrm{HCO}_{3}^{-}$buffer ( $\mathrm{pH} 9.6$ ) and $100 \mu \mathrm{l}$ of the diluted supernatants or of known concentrations of human LF were added to Nunc-Immuno 96 MicroWell Plates (Nalge Nunc International, Rochester, NY, USA) and incubated overnight at $4^{\circ} \mathrm{C}$. Non-specific-binding sites were blocked with PBS supplemented with $0.5 \%$ BSA and 0.5\% Tween-20. Plates were then treated with rabbit anti-human LF followed by peroxidase-conjugated anti-rabbit Ab. Each of the above steps was performed at room temperature, and between each step, the plates were repeatedly washed with TBS $+0.1 \%$
Tween-20. Color was developed with tetra-methyl-benzidene until optimum before the reaction was stopped with $50 \mu \mathrm{l}$ of a 1-M sulphuric acid. Absorbance was read at $450 \mathrm{~nm}$, and the LF concentration was calculated by comparison to the LF calibration curve.

\section{Biosynthesis of leukotrienes}

Cell suspensions $\left(10^{7}\right.$ neutrophils $/ \mathrm{ml}, \quad 10^{6}$ eosinophils or monocytes $/ \mathrm{ml}$ ) in HBSS with $1.6 \mathrm{mM}$ calcium were prewarmed $10 \mathrm{~min}$ by placing in a shaking water bath at $37^{\circ} \mathrm{C}$ prior stimulation for $5 \mathrm{~min}$ with fMLP $\left(10^{-7} \mathrm{M}\right)$, A23187 $\left(10^{-7} \mathrm{M}\right)$ or arachidonic acid $(2.5 \mu \mathrm{M})$ in the presence of $1 \mathrm{ng} / \mathrm{ml}$ of adenosine deaminase to neutralize the inhibitory effects of extracellular adenosine. ${ }^{31}$ For the determination of 5-lipoxygenase (5-LO)-derived products, cell supernatants were denatured by the addition of 0.5 volume of ice-cold $\mathrm{MeOH} / \mathrm{CH}_{3} \mathrm{CN}(1: 1, \mathrm{v} / \mathrm{v})$ containing $12.5 \mathrm{ng}$ each of $\mathrm{PGB}_{2}$ and $19-\mathrm{OH}-\mathrm{PGB}_{2}$ as internal standards, and the samples were processed and analyzed by reversed-phase (RP)-HPLC using an on-line extraction procedure, as described earlier. ${ }^{32}$ The 5-LO products leukotriene ( $\mathrm{LT}^{-} \mathrm{B}_{4}, 20-\mathrm{COOH}-\mathrm{LTB}_{4}, 20-\mathrm{OH}-$ $\mathrm{LTB}_{4}$, 6(E)-LTB, 6(E)-12-epi-LTB 4 , peptido-leukotrienes $\left(\mathrm{LTC}_{4}, \mathrm{LTD}_{4}\right.$ and $\left.\mathrm{LTE}_{4}\right)$ and 5-hydroxy-eicosatetraenoic acid (5-HETE) were evaluated. Limits of detection for the different lipoxygenase products were $2-5 \mathrm{ng}$.

Nuclear translocation of the 5- $\mathrm{LO}$ was evaluated as described earlier. ${ }^{33}$ Neutrophils $\left(2 \times 10^{7} / \mathrm{ml}\right)$ stimulated with fMLP or A23187, as above, were pelleted and resuspended in $600 \mu \mathrm{l}$ of ice-cold NP-40 lysis buffer $(0.1 \%$ NP-40, $10 \mathrm{mM}$ Tris-HCl, pH 7.4, $10 \mathrm{mM} \mathrm{NaCl}, 3 \mathrm{mM} \mathrm{MgCl}, 1 \mathrm{mM}$ EDTA, $10 \mathrm{mg} / \mathrm{ml}$ leupeptin, $10 \mathrm{mg} / \mathrm{ml}$ aprotinin and $1 \mathrm{mM}$ PMSF). The cells were vortexed for $15 \mathrm{~s}$, kept on ice for $5 \mathrm{~min}$ and centrifuged at $300 \mathrm{~g}\left(10 \mathrm{~min}, 4{ }^{\circ} \mathrm{C}\right)$. The supernatants, representing the non-nuclear fractions, and pellets, representing the nuclei-containing fractions, were then immediately solubilized in electrophoresis sample buffer and processed for SDSPAGE and immunoblot determination of the 5-LO protein content using a rabbit polyclonal anti-5-LO antibody.

\section{Phagocytosis of zymosan}

Phagocytic activity of neutrophils was measured using fluorescent zymosan A (membranes of Saccharomyces cerevisiae) bioparticles according to the manufacturer's instructions. Fluorescent particles were preopsonized in PBS containing $50 \%$ pooled human serum for $1 \mathrm{~h}$ at $37^{\circ} \mathrm{C}$ on a rotating mixer. Particles were washed, counted and added to $2.5 \times 10^{5}$ neutrophils (ratio cells/particles $=1 / 10$ ) in $100 \mu \mathrm{l}$ $\mathrm{RPMI}+0.1 \% \mathrm{FBS}$ for $10 \mathrm{~min}$ at $37^{\circ} \mathrm{C}$. Cells were washed and resuspended in $300 \mu \mathrm{l}$ RPMI $+0.1 \%$ FBS containing $10 \%$ trypan blue (added to quench the fluorescence of bioparticle conjugates bound to the surface, but not internalized). Ten thousand cells were evaluated by flowcytometry. The percentage of neutrophils that had internalized zymosan and the mean fluorescence intensity (MFI), a measurement of the number of particles taken up per cell, were assessed. 
The results were then expressed as a phagocytic index of neutrophils $=\%$ of neutrophils that had internalized zymosan $\times$ MFI. ${ }^{34}$ For microscopic evaluation of phagocytosis, cells were washed with PBS and labeled with $5 \mu \mathrm{g} / \mathrm{ml}$ of the calcein-AM probe at $37^{\circ} \mathrm{C}$ for $30 \mathrm{~min}$, washed and subsequently incubated with opsonized AlexaFluor594-conjugated zymosan A Bioparticles, as above. The cells were disposed on 8-well labtek chamber slides for confocal laser microscopy using the appropriate filter sets for the fluorochromes. Red and green images were merged to visualize internalized zymosan. Images were analyzed by using Volocity LE software from Improvision Inc. (Waltham, MA, USA).

\section{Biosynthesis of IL-1 $\beta, I L-1 R a$ and IL-8}

Neutrophils were incubated $\left(5 \times 10^{6} / \mathrm{ml}\right)$ in RPMI containing $10 \%$ decomplemented FBS in 12 -well plates $(2 \mathrm{ml} /$ well $)$ at $37^{\circ} \mathrm{C}, 5 \% \mathrm{CO}_{2}$, for $24 \mathrm{~h}$. Cell-free supernatants were collected after centrifugation and immediately stored at $-80^{\circ} \mathrm{C}$ until assayed for IL-1Ra, IL-1 $\beta$ and IL- 8 by commercially available kits according to manufacturers' instructions. Cell pellets were washed in PBS, centrifuged, resuspended in $1 \mathrm{ml}$ of PBS, sonicated $\left(20 \mathrm{~s}, 4^{\circ} \mathrm{C}\right)$ and these intracellular materials were immediately stored at $-80^{\circ} \mathrm{C}$ until assayed for cell-associated cytokines. Total cytokine production was obtained by addition of intracellular contents to supernatant contents. The IL8 and IL-1Ra assays used HRP as tracer, whereas the enzyme immunometric assay for the IL- $1 \beta$ used acetylcholine esterase as tracer. Concentrations of cytokines were obtained from standard curves generated by known concentrations of respective cytokines. The detection limits were 31,13 and $1.5 \mathrm{pg} / \mathrm{ml}$ for IL-1Ra, IL-8 and IL- $1 \beta$, respectively.

\section{Culture of Synovial Fibroblasts and Adhesion Assay}

Primary synovial fibroblasts obtained from post-traumatic hip replacement were maintained in a humidified atmosphere containing $5 \% \mathrm{CO}_{2}$ in Dulbecco's minimum essential medium supplemented with $2 \mathrm{mM}$ glutamine and $20 \%$ FBS. Fibroblasts were passaged by treatment with trypsin-EDTA and were used for tests within passage 5-15. For adhesion assays, fibroblasts were sub-cultured in 6-well plates $\left(5 \times 10^{5}\right.$ cells/well $)$ for a 48 -h period to obtain confluent monolayers. These fibroblasts were washed with PBS before adhesion assays. Neutrophils were labeled with $5 \mu \mathrm{g} / \mathrm{ml}$ of the fluorescent probe calcein-AM by incubation at $37^{\circ} \mathrm{C}$ for $30 \mathrm{~min}$. Labeled neutrophils with and without prior fMLP stimulation were added at a neutrophil/fibroblast ratio of 5/1 followed by incubation at $37^{\circ} \mathrm{C}$ for $90 \mathrm{~min}$. The non-adherent cells were removed by gentle aspiration. Fibroblasts and adherent neutrophils were washed repeatedly with PBS and observed under fluorescent microscope. The number of adherent cells were counted and presented as a mean of five separate fields/well.

\section{Statistics}

Values were expressed as means \pm s.e.m. of $n$ experiments performed with cells from different donors. Statistical analyses were performed using GraphPad Instat 3.0 (GraphPad Software, Inc., San Diego, CA, USA). Groups were analyzed by using paired or unpaired Student's $t$-test. Significance was set at two-tailed $P$ value $<0.05$.

\section{RESULTS \\ Individualization of a Neutrophil Subset Viable after Exposure to Cytokines}

Survival of cytokine-activated neutrophils

Circulating neutrophils from healthy human subjects were incubated in the presence and absence of GM-CSF, TNF- $\alpha$ and IL-4 in RPMI 1640 supplemented with 10\% decomplemented FBS. After 3 days of incubation, neutrophils were analyzed by flowcytometry after labeling with FITC-conjugated annexin- $\mathrm{V}$ and PI. Annexin- $\mathrm{V}$ binds to phosphatidylserine, a phospholipid externalized on the cell membrane of apoptotic cells, whereas necrotic cell nuclei are stained with PI, a DNA-chelating agent. Among the neutrophils exposed to cytokines for 3 days, a subset negative for annexin- $\mathrm{V}$ and PI that represented $13 \pm 5 \%$ of the whole population was consistently observed. This subpopulation of neutrophils represented $<2 \%$ of total cells in neutrophils incubated in RPMI $1640+10 \%$ FBS in the absence of the cytokines. Similar results were obtained with the release of cytosolic enzyme LDH, a cell death marker correlated with compromised membrane integrity.

To isolate this subset of neutrophils, cell debris, apoptotic and necrotic cells were separated from viable neutrophils by a discontinuous Percoll gradient centrifugation. Apoptotic and necrotic cells and cell debris were found at the cell suspension $/ 31 \%$ Percoll interface and the $31 / 42 \%$ Percoll interface. A mixture of apoptotic and non-apoptotic cells was found at the $42 / 51 \%$ Percoll interface. The cell pellet was predominantly constituted of non-apoptotic and non-necrotic cells (99\% of these cells routinely excluded trypan blue). Figure 1a shows the comparative profiles of annexin- $\mathrm{V}$ and PI labeling of cytokine-exposed cells before and after Percoll gradient centrifugation for a representative donor (9.3 and $84.1 \%$ viable cells, respectively). Similar results were obtained by testing the activity of neutrophil caspases, intracellular enzymes involved in apoptotic cell death. Before percoll separation, $88 \%$ of neutrophils showed positive caspase activity, whereas only $19 \%$ of Percoll-enriched cells had activated caspases (Figure 1b). DNA content was then analyzed in Percollenriched neutrophils using PI, a DNA-intercalating dye. A predominant G1 diploid peak was obtained with minimal apoptotic changes indicating that the identified neutrophil subset was terminally differentiated viable neutrophils with no cell division (results not shown). This viable subset of Percoll-enriched neutrophils isolated from cytokine-exposed neutrophils was routinely used in subsequent functional 
Long-lived neutrophils

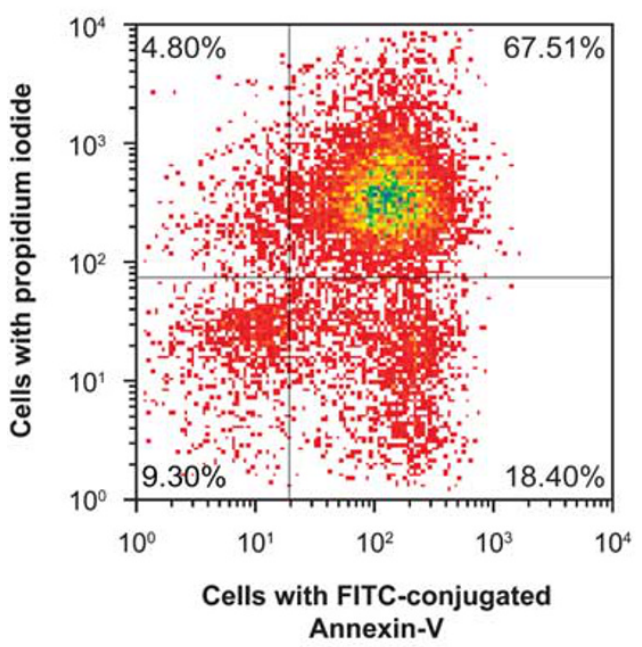

Percoll-enriched

long-lived neutrophils

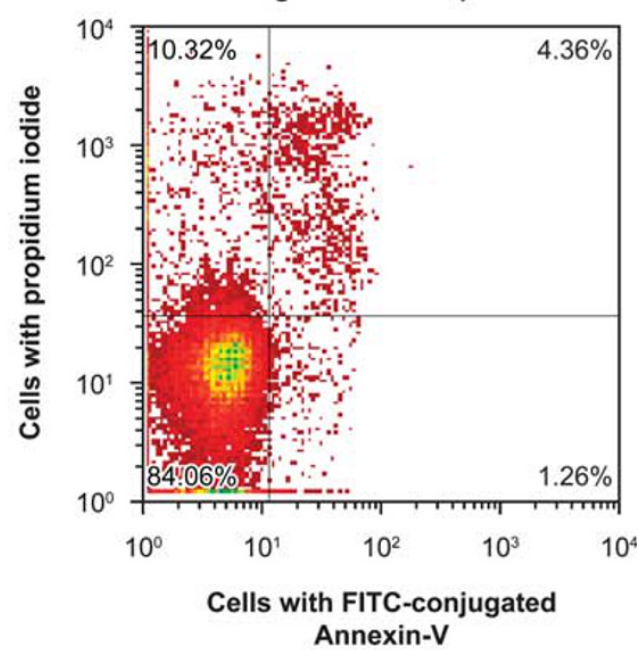

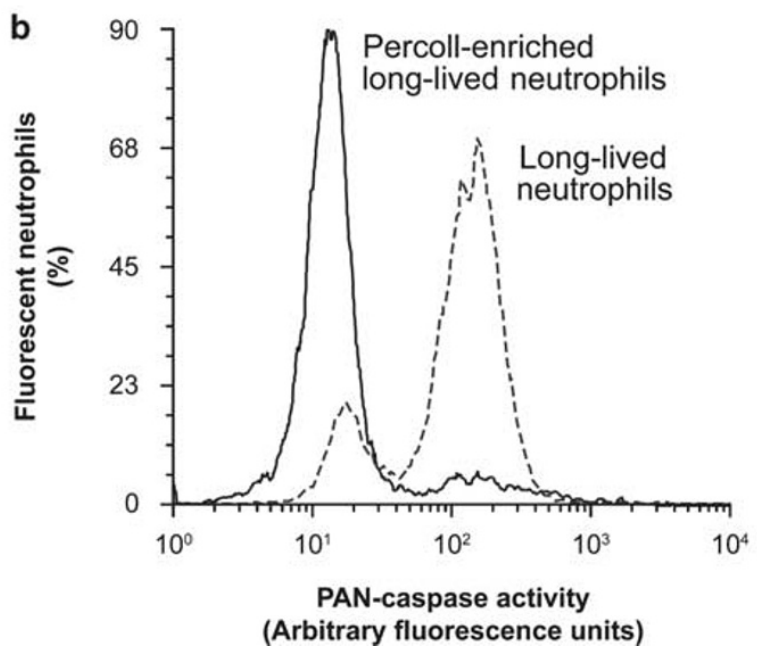

Figure 1 Enrichment of viable neutrophils by Percoll gradient centrifugation. Freshly isolated neutrophils ( $10^{7}$ cells $/ \mathrm{ml}$ ) were incubated with GM-CSF, IL-4 and TNF- $\alpha$ for 3 days. The viable neutrophils were then enriched by eliminating dead cells and debris through a Percoll gradient centrifugation. (a) Viability of incubated neutrophils assessed before and after Percoll gradient centrifugation by annexin-V and PI labeling. (b) Viability of long-lived neutrophils before (dashed line) and after (plain line) enrichment by Percoll gradient centrifugation was also assessed by intracellular pancaspase activity. Figures (a) and (b) are representative of five different donors.

assays and referred to in the text below as long-lived neutrophils.

\section{Morphology of long-lived neutrophils}

Microscopy after different staining methods of long-lived neutrophils revealed a morphology similar to that of freshly isolated neutrophils with hypersegmented nuclei and cytoplasmic granules. Promyelocytes, myelocytes and band cells that lack this polylobar nuclear morphology ${ }^{35}$ were absent from our neutrophil preparations. Non-specific esterasepositive cells were absent, whereas eosinophils represented $2-5 \%$ in freshly isolated neutrophils. After 3 days of incubation, monocytes and lymphocytes were not detectable by microscopy, whereas eosinophils represented $2-4 \%$ of long-lived neutrophils. Of note and in concordance with viability results (see above), long-lived neutrophils lacked morphological alterations of apoptosis such as chromatin condensation and nuclear pyknosis. ${ }^{36}$ Transmission electron micrographs of freshly isolated neutrophils (Figure 2a) and long-lived neutrophils (Figure 2b) showed similar morphology of plasma membranes, intra-cytoplasmic organites and nuclear segmentation.

\section{Modification of surface markers of long-lived neutrophils}

Cytokine exposure modifies surface molecule expression in neutrophils. ${ }^{37}$ The majority of long-lived neutrophils (98-99\%) expressed CD11b, CD18 and CD32 as analyzed by flowcytometry (Table 1). The percent expression was similar to that of freshly isolated neutrophils, whereas the MFI of these molecules was decreased. These cells also showed a 

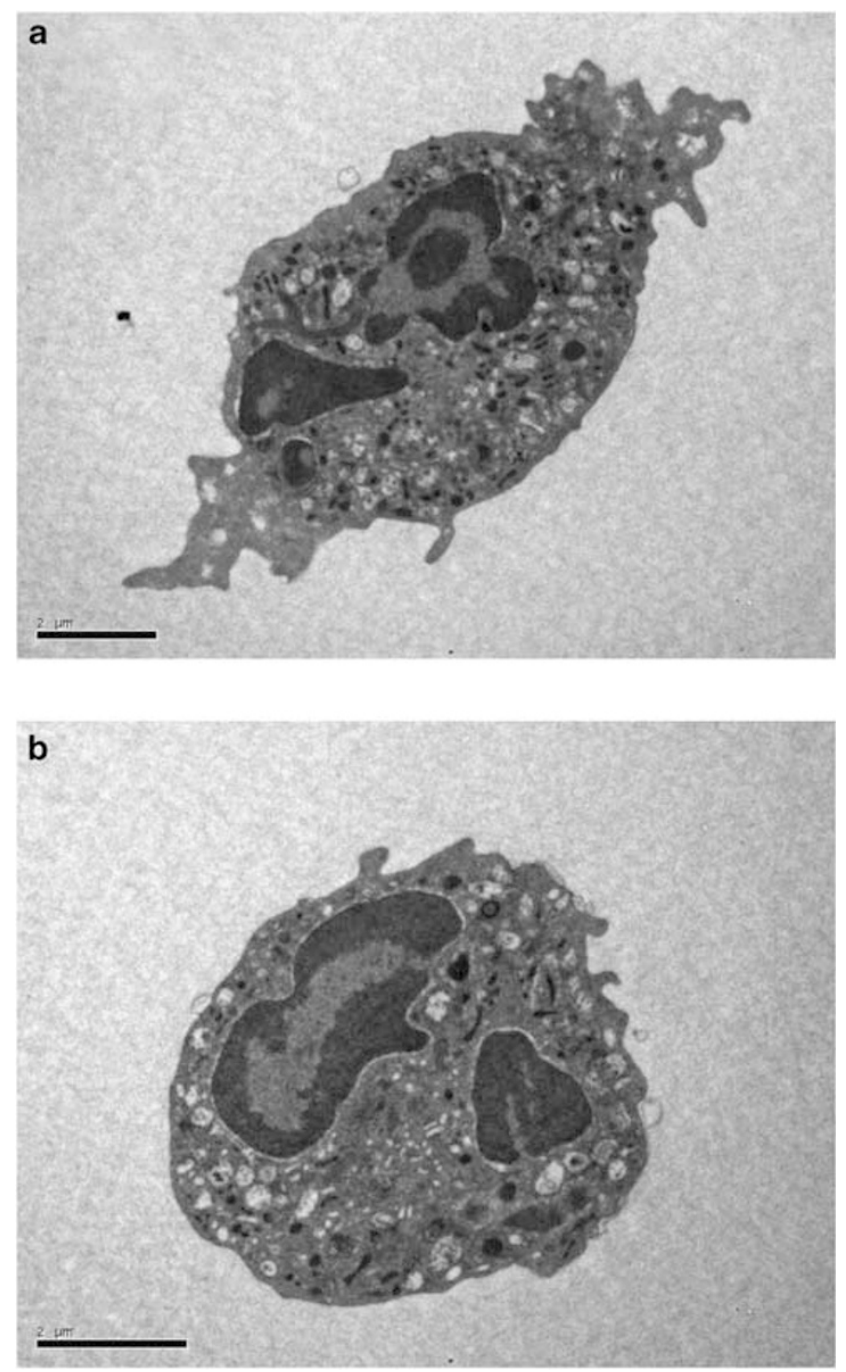

Figure 2 Electron microscopy of human neutrophils. Freshly isolated (a) and long-lived neutrophils (b) were spun onto slides and fixed in $4 \%$ paraformaldehyde and $2.5 \%$ glutaraldehyde. After postfixation in $1 \% \mathrm{OsO}_{4}$, the samples were dehydrated and embedded in Epon. Ultrathin sections were transferred to a 200-mesh nickel/Formvar grid and stained with $3 \%$ uranyl acetate/lead citrate to be examined in a JEM-1230 microscope. unique profile of expression of integrins with neoexpression of CD49d, the $\alpha 4$ subunit of the integrin VLA-4 (Figure 3). In comparison to freshly isolated neutrophils, long-lived neutrophils had an augmented MFI of CD54 (ICAM-1) and a strong reduction of CD29 ( $\beta 1$ integrin) surface expression (Table 1). Interestingly, long-lived neutrophils had a neoexpression of HLA-DR and CD80 (Figure 3; Table 1), molecules that characterize antigen-presenting cells.

\section{Functional Characterization of Long-Lived Neutrophils Production of $\mathrm{O}_{2}^{-}$}

The fMLP increased the production of $\mathrm{O}_{2}^{-}$in long-lived neutrophils three to four times more efficiently than in freshly isolated neutrophils $\left(40.7 \pm 10.7 \mathrm{nM} / 10^{6}\right.$ cells $/ \mathrm{ml} v \mathrm{~s}$ $11.0 \pm 2.9 \mathrm{nM} / 10^{6}$ cells $/ \mathrm{ml}$, respectively; $P=0.019$ ). Superoxide generation by freshly isolated neutrophils was in the range of results from other groups. ${ }^{38}$ Interestingly, long-lived neutrophils produced similar amounts of $\mathrm{O}_{2}^{-}$under fMLP and under PMA (Figure 4a). PMA stimulated the $\mathrm{O}_{2}^{-}$production to a similar extent in the two neutrophil populations. In contrast, the $\mathrm{O}_{2}^{-}$generation in response to $\mathrm{A} 23187$ was greatly diminished in long-lived neutrophils. As $2-4 \%$ (20-40 000) eosinophils were present in long-lived neutrophils, similar experiments were also performed with this cell type to confirm that long-lived neutrophils were different from eosinophils. After 3 days of exposure to cytokines, pure eosinophils were, however, incubated at concentrations similar to those of long-lived neutrophils to be able to detect $\mathrm{O}_{2}^{-}$production. Cyokine-exposed eosinophils in presence of fMLP produced three times lower quantities of $\mathrm{O}_{2}^{-}$ $\left(16.3 \pm 3.3 \mathrm{nM} / 10^{6}\right.$ cells $\left./ \mathrm{ml}\right)$ than did long-lived neutrophils (Figure 4b). Moreover, their response to PMA was also lower than that of long-lived neutrophils. In addition, monocytes under fMLP or PMA produced negligible $\mathrm{O}_{2}^{-}(1.5 \pm 2.9 \mathrm{nM} /$ $10^{6} / \mathrm{ml}$ and $4.1 \pm 0.4 \mathrm{nM} / 10^{6} / \mathrm{ml}$, respectively). These results indicate that long-lived neutrophils have a distinct capacity to produce $\mathrm{O}_{2}^{-}$depending on the stimulatory agents.

Table 1 Cell surface phenotype of freshly isolated and long-lived neutrophils

\begin{tabular}{|c|c|c|c|c|c|}
\hline \multirow{2}{*}{ Neutrophil surface markers } & CD11b & $99.8 \pm 0.2$ & $155.9 \pm 33.2$ & $98.3 \pm 0.1$ & $20.8 \pm 13.2^{* *}$ \\
\hline & CD32 & $99.9 \pm 0.1$ & $46.8 \pm 8.9$ & $99.0 \pm 0.1$ & $16.0 \pm 2.9$ \\
\hline Adhesion molecules & CD29 & $93.6 \pm 0.4$ & $3.4 \pm 0.9$ & $7.8 \pm 2.4^{* * *}$ & $3.8 \pm 1.6$ \\
\hline
\end{tabular}

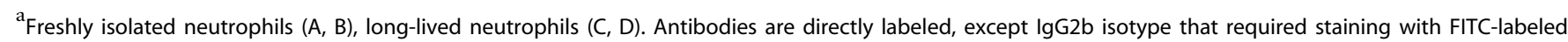

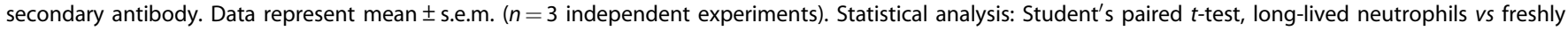
isolated neutrophils $\left({ }^{\star} P<0.02,{ }^{* *} P<0.005,{ }^{* *} P<0.0001\right)$. 


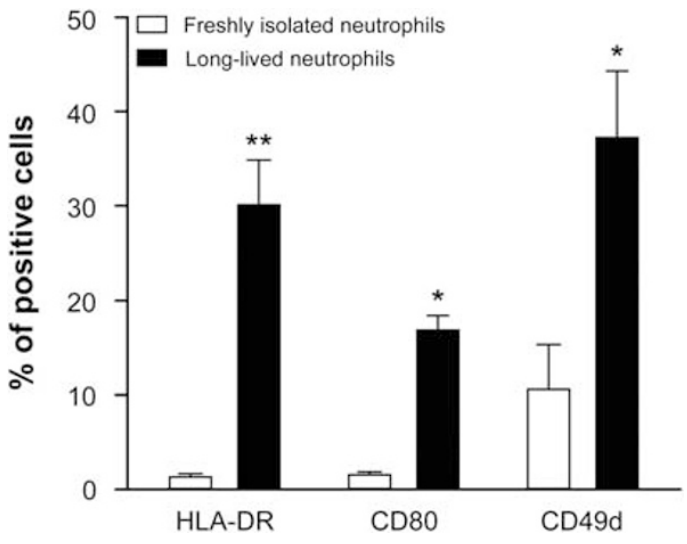

Figure 3 Surface expression of HLA-DR, CD80 and CD49d by neutrophils. Percoll-enriched long-lived neutrophils $\left(10^{6}\right.$ cells) were marked with unconjugated primary antibody against HLA-DR and CD80 followed by staining with FITC-labeled secondary antibody, or directly stained with FITC-labeled anti-CD49d antibody before flowcytometry. Data are expressed in percentage of cells and represent mean \pm s.e.m. $(n=3)$. Statistics: Student's paired two-tailed $t$-test (freshly isolated neutrophils vs long-lived neutrophils); ${ }^{*} P<0.05,{ }^{* *} P<0.02$.

\section{Chemotaxis}

Chemotactic responses of long-lived neutrophils to fMLP, $\mathrm{LTB}_{4}$ and IL-8 were studied. These factors are known to efficiently activate chemotaxis of human blood neutrophils. ${ }^{39}$ Freshly isolated neutrophils responded to these chemoattractants with characteristic biphasic curves that showed maximal neutrophil responses at $10^{-7} \mathrm{M}$ for fMLP (Figure 5a) and $\mathrm{LTB}_{4}$ (data not shown) and $10^{-8} \mathrm{M}$ for IL-8 (data not shown). In contrast, long-lived neutrophils migrated significantly less than freshly isolated neutrophils toward chemotactic factors. Percentages of neutrophil migration were greatly reduced for the three agonists tested. For example, $10.2 \pm 3.9 \%$ long-lived neutrophils migrated in response to $10^{-7} \mathrm{M}$ fMLP instead of $49.8 \pm 1.6 \%$ of freshly isolated neutrophils (Figure 5a). Similarly, long-lived neutrophils $v s$ freshly isolated neutrophils had a reduced migration response toward $\mathrm{LTB}_{4}(5.3 \pm 1.1 \%$ vs $51.2 \pm 1.2 \%$, respectively) and IL-8 (4.1 $\pm 1.6 \%$ vs $49.8 \pm 0.3 \%$, respectively). Chemotactic data obtained using polycarbonate filters with $8 \mu \mathrm{m}$ pore size were similar to those obtained with $3 \mu \mathrm{m}$ pore size (data not shown), indicating that the observed reduction of migration was not related to changes in cell size of longlived neutrophils.

\section{Exocytosis of primary and secondary granules}

The release of MPO contained in primary granules and of LF prestocked in secondary granules by long-lived and freshly isolated neutrophils was evaluated in response to fMLP, PMA or A23187. Freshly isolated neutrophils released MPO in supernatants when stimulated by fMLP $(639 \pm 96 \mathrm{mU} / \mathrm{min})$, PMA $(300 \pm 29 \mathrm{mU} / \mathrm{min})$ and A23187 $(476 \pm 24 \mathrm{mU} / \mathrm{min})$ with respect to vehicle $(155 \pm 22 \mathrm{mU} / \mathrm{min})$ alone. In contrast, none of the abovementioned agonists significantly affected
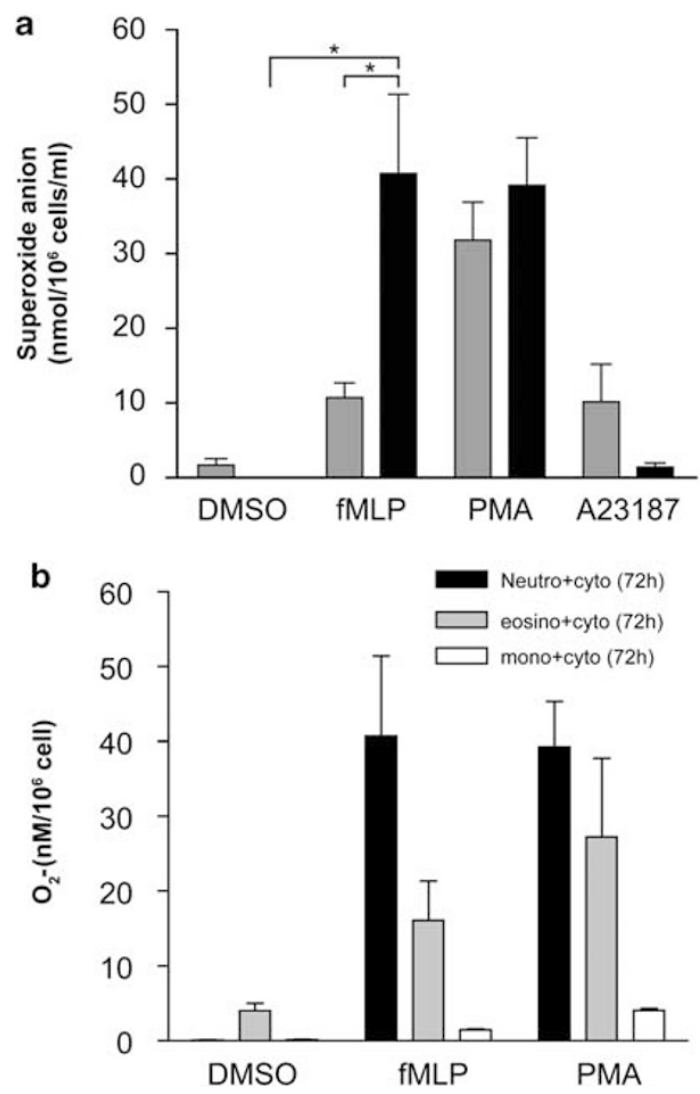

Figure $4 \mathrm{O}_{2}^{-}$production by human leukocytes. (a) After preincubation with cytochrome $c$, freshly isolated neutrophils (gray columns) and longlived neutrophils (black columns) were stimulated with vehicle (DMSO), $10^{-7} \mathrm{M}$ fMLP, PMA or ionophore A23187 for $5 \mathrm{~min}$ at $37^{\circ} \mathrm{C}$. The release of extracellular reactive oxygen $\left(\mathrm{O}_{2}^{-}\right)$was calculated in nmol of oxygen for $10^{6}$ cells (see details in Materials and methods). The results are means \pm s.e.m. $(n=5)$. Statistics: Student's paired two-tailed $t$-test $\left({ }^{*}>0.05\right.$ : unstimulated $v s$ fMLP-stimulated long-lived neutrophils or fMLP-stimulated freshly isolated neutrophils vs $\mathrm{FMLP}$-stimulated long-lived neutrophils). (b) Incubations with cytokines similar to those of long-lived neutrophils were conducted with human eosinophils and monocytes. Cells were then stimulated with DMSO, $10^{-7} \mathrm{M}$ fMLP or PMA for $5 \mathrm{~min}$ at $37^{\circ} \mathrm{C}$. The release of extracellular reactive oxygen $\left(\mathrm{O}_{2}^{-}\right)$was calculated in nmol of oxygen for $10^{6}$ cells. The results are means \pm s.e.m. ( $n=5$ : PMN, $n=3$ : eosinophils and monocytes).

MPO release by long-lived neutrophils (Figure 5b). On the other hand, long-lived neutrophils had an increased spontaneous release of LF, but none of the agonists triggered an augmented release of LF by long-lived neutrophils, even in the presence of cytochalasin B (Figure 5c). This is in contrast to freshly isolated neutrophils in which LF release is significantly augmented with stimulations (213, 209 and 154\% of vehicle for PMLP, PMA and A23187, respectively, in the presence of cytochalasin B used to amplify degranulation response). These results indicate that long-lived neutrophils have a low spontaneous release of MPO similar to that of circulating neutrophils, have an increased spontaneous release of LF, but remain insensitive to exogenous stimuli to increase this release. 


\section{Phagocytosis of opsonized zymosan particles}

Neutrophils are avid phagocytes, phagocytosis of particles being a function essential to host defense during immune and inflammatory reactions. ${ }^{1}$ The capacity of long-lived and freshly isolated neutrophils to phagocytize opsonized fluorescent zymosan bioparticles was compared by flow cytometry (Figure 6a and b) and confocal laser microscopy (Figure 6c). The fluorescence of non-internalized, surface-bound bioparticle conjugates was quenched by trypan blue. The percentage of neutrophils that had internalized zymosan, as well as MFI directly related to the number of particles taken
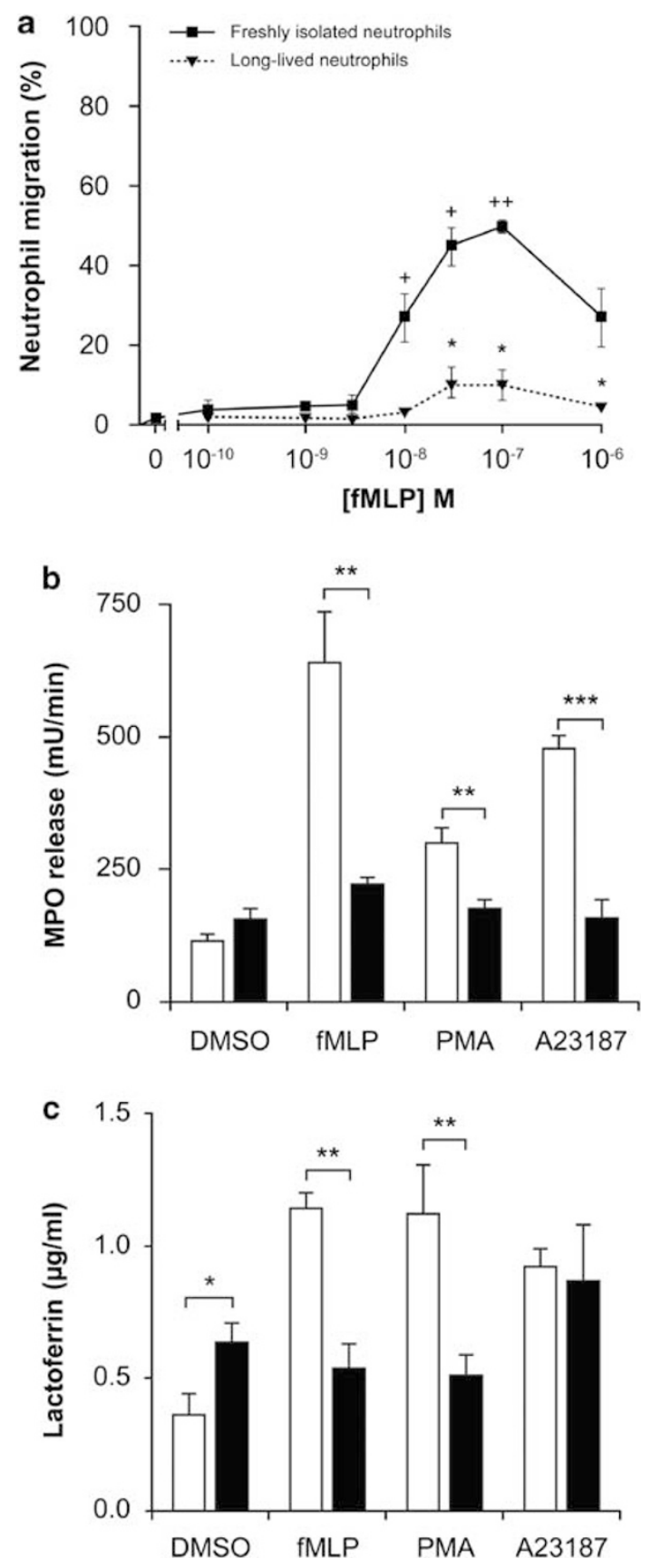

up per cell, were assessed. Phagocytosis of opsonized zymosan by long-lived neutrophils was more efficient than phagocytosis of these particles by freshly isolated neutrophil (Figure 6a). A $141 \%$ increase of the phagocytic index of long-lived neutrophils was noted relative to freshly isolated neutrophils (Figure 6b). Both the percentage of phagocytozing cells and the MFI per cell were augmented with respect to freshly isolated cells. Of note, Figure $6 c$ shows multiple zymosan particles (seen in red) easily visualized in a single phagocytozing long-lived neutrophil (seen in green). Thus, long-lived neutrophils have an augmented capacity to phagocytize particles.

\section{Production of leukotrienes}

Neutrophils are major purveyors of $\mathrm{LTB}_{4}$, a bioactive lipid derived from arachidonic acid that is strongly involved in patho-physiology. ${ }^{40,41}$ The profile of 5-lipoxygenase products was characterized by RP-HPLC in long-lived neutrophils. ${ }^{32}$ Freshly isolated and long-lived neutrophils incubated in control conditions with the diluent DMSO did not produce any detectable amounts of $\mathrm{LTA}_{4}$-derived metabolites (data not shown). Freshly isolated neutrophils responded minimally to fMLP in terms of leukotriene synthesis. In contrast, long-lived neutrophils stimulated with fMLP produced large amounts of $\mathrm{LTA}_{4}$-derived metabolites (Figure 7a). Surprisingly, the most important part of these $\mathrm{LTA}_{4}$-derived metabolites was composed of the $\Delta 6$-trans isomers of $\mathrm{LTB}_{4}$ $(35.8 \pm 14.9 \mathrm{pmol})$, compared with $5.8 \pm 2.9 \mathrm{pmol} \mathrm{LTB}_{4}$ and $2.7 \pm 0.9$ pmol $20-\mathrm{OH}-\mathrm{LTB}_{4}(n=5)$. Long-lived neutrophils did not respond to exogenous arachidonic acid (Figure 7b), and their response to A23187 was significantly diminished (Figure 7c). Finally, long-lived neutrophils also generated 5-HETE with, however, a very different profile of synthesis compared with freshly isolated neutrophils (Figure 7d). The

Figure 5 Chemotactic and exocytosis functions of long-lived neutrophils. (a) Neutrophils charged with calcein-AM were stimulated to migrate across filters using concentration gradient of fMLP. The results are expressed in percentages (mean \pm s.e.m. of triplicates) of fluorescent cells that migrated through the filter with respect to the total number of cells loaded. Statistics: Student's unpaired $t$-test of two separate experiments $\left({ }^{+} P<0.05\right.$, ${ }^{++} P<0.01$ with respect to vehicle; ${ }^{\star} P<0.05$ with respect to fMLP stimulation of freshly isolated neutrophils at equal molar concentrations of $\mathrm{fMLP}$ ). (b) Secretion of MPO by neutrophils. Freshly isolated neutrophils $(\square)$ and long-lived neutrophils $(\mathbf{\square})$ at $5 \times 10^{6} \mathrm{cells} / \mathrm{ml}$ were stimulated with vehicle, $f M L P, P M A$ or ionophore $A 23187$ at a final concentration of $10^{-7} \mathrm{M}$ for $5 \mathrm{~min}$ in the presence of $1 \mu \mathrm{g} / \mathrm{ml}$ cytochalasin B. The results are expressed in $\mathrm{mU} / \mathrm{min}$ of MPO released in the supernatants and are displayed as means \pm s.e.m. $(n=4)$. Statistics were performed using Student's unpaired $t$-test $\left.{ }^{* * P}<0.02,{ }^{* * *} P<0.001\right)$. (c) Secretion of LF by neutrophils. Freshly isolated neutrophils $(\square)$ and long-lived neutrophils (घ) at $10^{5}$ cells $/ \mathrm{ml}$ were stimulated similar to (b). LF released in supernatants was determined by ELISA. The results are expressed in $\mathrm{ng} / \mathrm{ml}$ as means \pm s.e.m. of four donors (freshly isolated neutrophils) and five donors (long-lived neutrophils). Statistics were performed using Student's unpaired $t$-test $\left({ }^{*} P<0.05,{ }^{* *} P<0.02\right)$. 


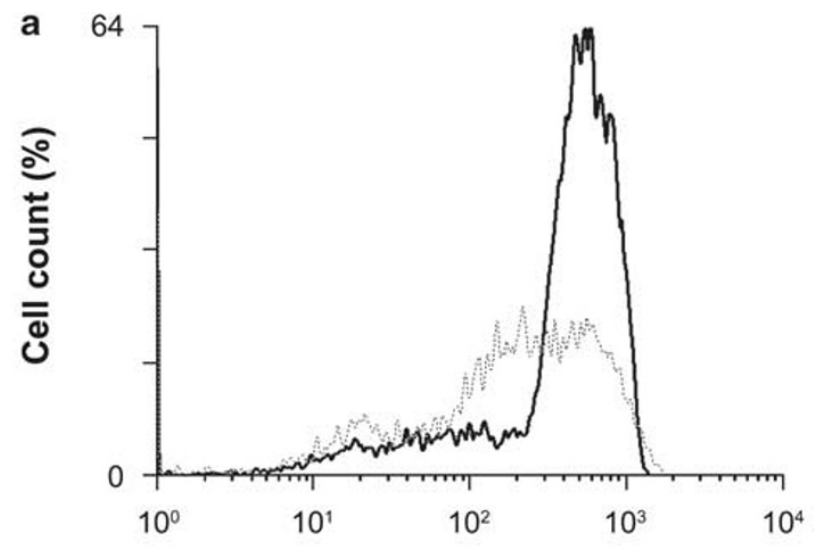

Fluorescence (arbitrary units)
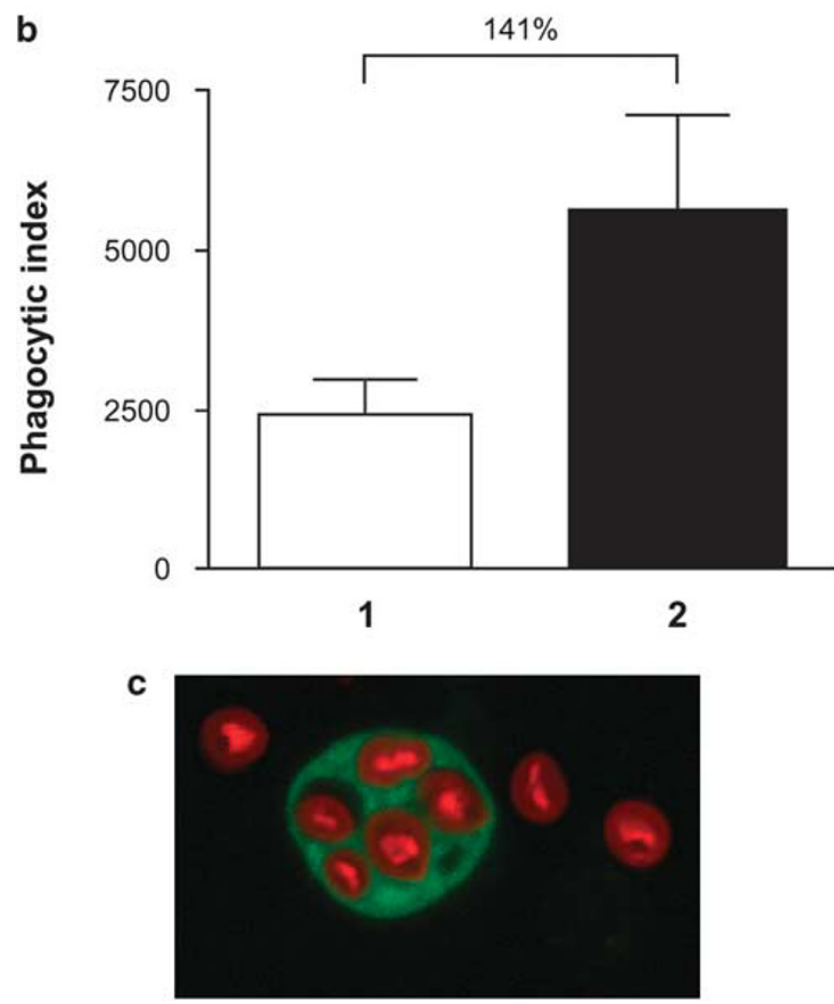

Figure 6 Phagocytosis of opsonized zymosan particles by neutrophils. (a) Flowcytometry of freshly isolated neutrophils (dashed tracing) and long-lived neutrophils (solid tracing). Cells were incubated with opsonized FITC-conjugated zymosan bioparticles for $10 \mathrm{~min}$ at $37^{\circ} \mathrm{C}$ using a neutrophil/zymosan ratio of $1 / 10$. Data shown are representative of three separate experiments. (b) Histograms show the phagocytic index (calculated as $\%$ of neutrophils that had internalized zymosan $\times$ MFI) of freshly isolated neutrophils (bar 1) and long-lived neutrophils (bar 2). The results are means \pm s.e.m. Statistics: phagocytic index of long-lived vs freshly isolated neutrophils is significantly different with $P<0.02$ (Student's unpaired $t$-test, $n=3$ ). (c) Visualization of zymosan phagocytosis by longlived neutrophils. Cells labeled with calcein-AM $(490 / 515 \mathrm{~nm})$ were incubated with opsonized Alexa Fluor 594-conjugated zymosan bioparticles $(590 / 617 \mathrm{~nm})$ for $10 \mathrm{~min}$ similar to (a). Cells were observed by confocal laser microscropy using appropriate filters (magnification $\times 100$ ).
fMLP stimulation was associated with a significant increase of 5-HETE that was not present in freshly isolated neutrophils. A23187 minimally induced 5-HETE production, as compared with the freshly isolated counterpart. Moreover, no accumulation of 5-HETE was observed in long-lived neutrophils in the presence of arachidonic acid, a pattern completely different from that of freshly isolated neutrophils. Similar experiments were also conducted with cytokineexposed eosinophils (results not shown). In comparison to long-lived neutrophils, cytokine-exposed eosinophils synthesized six times less $\mathrm{LTB}_{4}$ in response to $\mathrm{A} 23187$, and their $\mathrm{LTB}_{4}$ production in response to $\mathrm{MLP}$ and arachidonic acid was undetectable by RP-HPLC. However, they generated peptido-leukotrienes $(3.6 \pm 0.9,13.5 \pm 1.0$ and $2.6 \pm 1.5 \mathrm{ng}$ in response to fMLP, A23187 and arachidonic acid, respectively, $n=3$ ). Long-lived neutrophils did not produce peptidoleukotrienes in any of the above conditions, as analyzed by RP-HPLC.

Activation of 5-LO induced by A23187 or fMLP is associated with the nuclear translocation of the enzyme. ${ }^{42}$ The next step was to verify whether the augmented leukotriene synthesis observed in fMLP-stimulated long-lived neutrophils was related to the activation of 5-LO through its translocation to the nuclear fraction. Immunoblot determination of the 5-LO protein content revealed an increased translocation of the 5-LO to the nuclear fraction of long-lived neutrophils compared with that of freshly isolated neutrophils (Figure 7e). In contrast, the nuclear fractions of A23187and arachidonic acid-stimulated long-lived neutrophils were almost devoid of 5-LO. It is also interesting to note that, in long-lived neutrophils, a portion of 5-LO was already associated to the nuclear membrane in the absence of stimulation.

\section{Production of IL-1 $\beta, I L-8$ and IL-1Ra}

Neutrophils can be a source of various cytokines during the inflammatory process, ${ }^{43}$ and given the sheer number of neutrophils at an inflammatory site, such neutrophil-derived cytokines can greatly impact on the local process. The presence of cytokines produced was evaluated in cell-free supernatants and cell-associated materials of long-lived neutrophils and freshly isolated neutrophils incubated with or without fMLP.

Unstimulated long-lived neutrophils (column 2 of histograms) had a remarkable capacity for biosynthesis of the three cytokines (Figure 8). Production of IL-1Ra by longlived neutrophils was 20 times higher than that of freshly isolated cells, and production of IL-8 was 32 times higher in long-lived neutrophils (Figure $8 \mathrm{a}$ and $\mathrm{b}$ ). In addition, whereas there was no detectable IL- $1 \beta$ synthesis in freshly isolated neutrophils, long-lived cells produced $24 \pm 11 \mathrm{pg} / \mathrm{ml}$ of this cytokine (Figure 8c). The fMLP stimulation, however, did not affect release of IL-1 $\beta$ and IL-1Ra in both types of neutrophils (results not shown). Though fMLP robustly increased IL-8 release in both freshly isolated and long-lived 

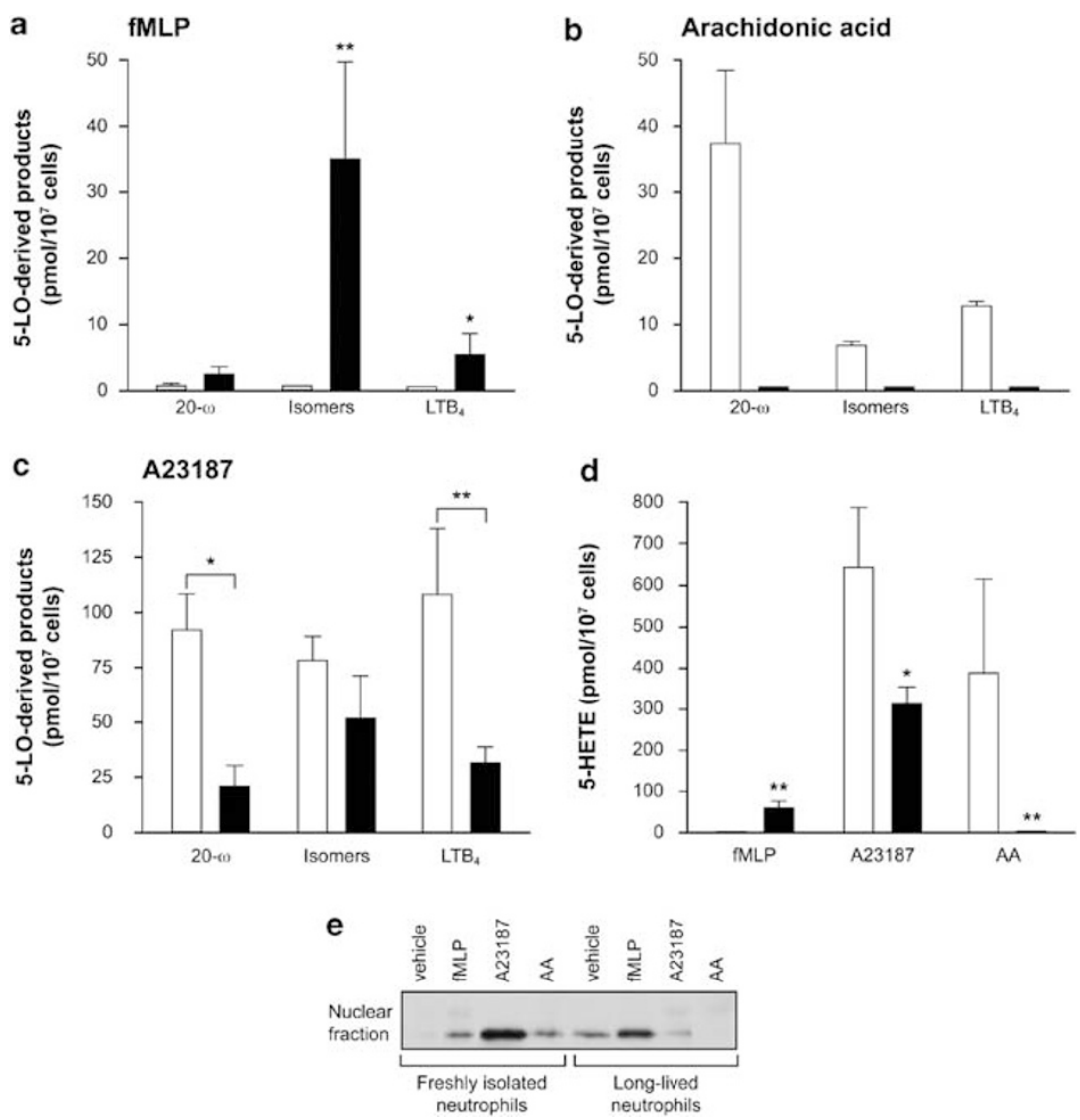

Figure 7 Leukotriene biosynthesis by neutrophils. Biosynthesis of $\mathrm{LTA}_{4}$-derived metabolites was evaluated in freshly isolated neutrophils ( $\square$ ) and longlived neutrophils ( $\mathbf{a})$ stimulated by $10^{-7} \mathrm{M} \mathrm{fMLP}(\mathbf{a}), 2.5 \mu \mathrm{M}$ arachidonic acid (b) and $10^{-7} \mathrm{M}$ ionophore A23187 (c) using RP-HPLC. (d) 5-HETE accumulated by freshly isolated and long-lived neutrophils in conditions $(\mathbf{a}, \mathbf{b}, \mathbf{c})$ was also assessed by RP-HPLC. The results are means \pm s.e.m. of five independent experiments for $\mathrm{FMLP}$ and A23187, and three independent experiments for arachidonic acid (AA). Statistics: Student's unpaired two-tailed $t$-test: long-lived neutrophils vs freshly isolated neutrophils $\left({ }^{*} P<0.05,{ }^{*} P<0.02\right)$. (e) Nuclear fractions of cells $\left(2 \times 10^{7}\right)$ were prepared by lysis in NP-40 buffer and centrifugations. Subsequently, SDS-PAGE and immunoblots were performed with rabbit polyclonal anti-5-LO antibodies. The figure is representative of three different experiments.
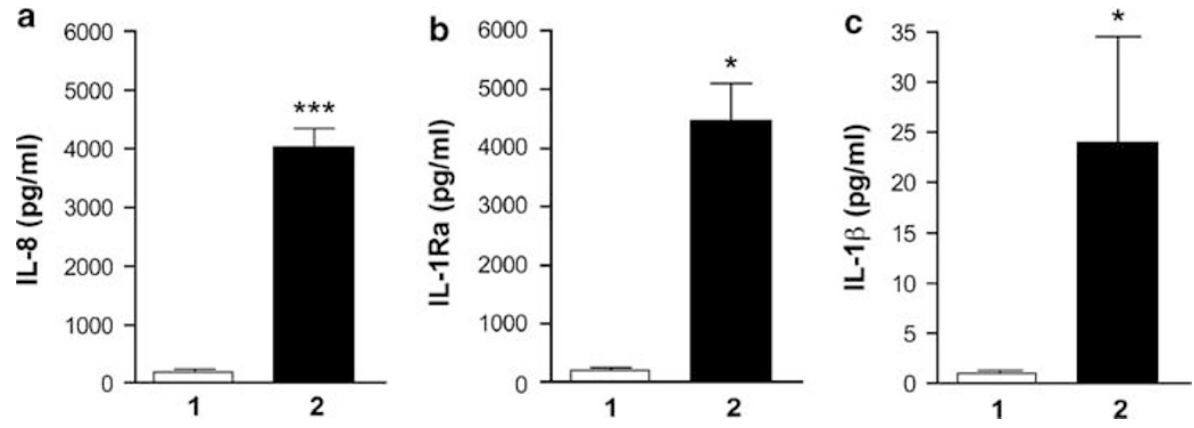

Figure 8 Release of IL-1 $\beta$, IL-8 and IL-1Ra by long-lived neutrophils. Freshly isolated neutrophils (bar 1) and long-lived neutrophils (bar 2 ) were incubated at $5 \times 10^{6} / \mathrm{ml}$ for $24 \mathrm{~h}$. IL-1 $\beta$ (c), IL-1Ra (b) and IL-8 (a) were measured in supernatants using enzyme immunometric assays. The results are means \pm s.e.m. of three donors (freshly isolated neutrophils) and five donors (long-lived neutrophils). Statistics: Student's unpaired $t$-test for freshly isolated neutrophils vs long-lived neutrophils $\left({ }^{*} P<0.05,{ }^{* * *} P<0.001\right)$.

neutrophils, this was accompanied by significant decline in intracellular IL-8 stores (results not shown). Thus, fMLP acted only as a secretagogue and did not influence de novo synthesis of IL-8 in these cells.
In addition to cytokine release shown in Figure 8, the total production of these cytokines by long-lived neutrophils was also greatly increased relative to freshly isolated neutrophils. Whereas freshly isolated neutrophils synthesized $868 \pm 203 \mathrm{pg} / \mathrm{ml}$ of IL-8, 
production of IL-8 was about 9.25 times more elevated in longlived cells $(8025 \pm 482 \mathrm{pg} / \mathrm{ml})$. IL-1Ra production was about 5.7 times increased in long-lived cells $(9513 \pm 2603 \mathrm{pg} / \mathrm{ml}) \mathrm{com}$ pared with freshly isolated cells $(1659 \pm 367 \mathrm{pg} / \mathrm{ml})$. IL- $1 \beta$ was not detectable in the cell-associated materials of both neutrophil populations. This points to a de novo biosynthesis of IL-8, IL-1Ra and IL- $1 \beta$ in these cells.

\section{Adhesion to primary human fibroblasts}

The interactions between immune cells and fibroblasts have a critical function in host defense or tissue injury. ${ }^{44-46}$ The next set of experiments was aimed at verifying whether long-lived neutrophils have the potential to interact with primary human fibroblasts. Neutrophils prelabeled with calcein-AM were incubated with confluent synovial fibroblasts and adherent neutrophils were observed by fluorescent microscopy. Freshly isolated neutrophils had a very low capacity to adhere on fibroblasts with or without stimulation by fMLP (Figure $9 \mathrm{a}$ and $\mathrm{b}$ ). In contrast, long-lived neutrophils spontaneously adhered on cultured fibroblasts (58 \pm 3 cells), and the number of adherent neutrophils was drastically increased in the presence of fMLP ( $364 \pm 15$ cells). The adhesion induced by fMLP was 50 times more elevated for long-lived neutrophils than for freshly isolated neutrophils. Interestingly, similar results were obtained by studying the adherence of long-lived neutrophils on MG-63 cells, another stromal cell type with osteoblastic characteristics (data not shown).

\section{Proteome profile of phosphorylated serine-threonine kinases}

The prolonged survival of long-lived neutrophils suggests cytokine-induced activation of intracellular signaling cascades delivering anti-apoptotic signals. As several protein kinases of the serine/threonine family are implicated in neutrophil survival, ${ }^{10,47}$ phosphorylation of these kinases was compared in long-lived neutrophils $v s$ freshly isolated neutrophils.

Lysates of long-lived neutrophils and freshly isolated neutrophils were incubated on nitrocellulose membranes impregnated with capture and control antibodies. Membranes were then probed with a cocktail of phospho-sitespecific biotinylated antibodies and the relative amounts of phosphorylation of serine-threonine kinases were quantitated by densitometric measurements of the dot blots using ImageJ software. A robust phosphorylation of $\mathrm{p} 38 \delta$ MAP kinase, GSK (glycogen synthase kinase)-3 $\alpha / \beta$, RSK (ribosomal protein S6 kinase)-1 and Akt1 and 2 was identified in long-lived neutrophils compared with freshly isolated neutrophils (Panel 2 vs 1, Figure 10a). The relative change in phosphorylation status of these kinases (long-lived neutrophils $v s$ freshly isolated neutrophils) shows a nine-fold increase in p38 $\delta$ MAP kinase, a 2.3-fold increase in RSK-1, a 2.6-fold increase in GSK$3 \alpha / \beta$, a 12 -fold increase in Akt1 and a 82-fold increase in Akt2 phosphorylation (Figure 10b). MSK2 and Akt pan phosphorylation are increased in freshly isolated neutrophils only. ERK1, 2,
JNK1, 2, 3 and $\mathrm{p} 38 \alpha, \beta$ and $\gamma$ MAP kinases are minimally stimulated in both types of neutrophils.

\section{DISCUSSION}

The ability of leukocytes to switch phenotype is an essential property of the adaptive immune system. In particular, the microenvironment can activate such switch that drives cells to change their effector responses orienting host defenses and disease evolution. In this work, we show reprogramming in a cell traditionally associated with the innate immune system: the neutrophil. In response to combined cytokines enhancing survival, a subset of normal human blood neutrophils changes its effector functions. Derived from highly pure neutrophil preparations, this CD66b-positive population resembling the circulating neutrophil in morphology and staining characteristics, lives longer, responds differentially to second stimuli and has a phenotype vastly different from starting populations. Centrifugation on discontinuous Percoll gradients allowed isolation of this subpopulation of neutrophils from contaminating dead cells, debris, necrotic and apoptotic cells that could interfere with functional studies.

Inflammatory reprogramming increases neutrophil viability. Indeed, they exclude markers of different stages and different mechanisms of cell death, annexin- $V$ and caspases being early cell death markers and PI incorporation being indicative of late apoptosis and necrosis. As shown herein, $8-17 \%$ neutrophils of the global neutrophil population have the potential to persist for $>72 \mathrm{~h}$ under inflammatory conditions. This is in stark contrast to the circulating neutrophils whose survival is measured in hours. What would be the mechanisms of this persistence? We opted to explore this issue through global measure of intracellular protein phosphorylation, given that the protein kinases have been largely implicated in neutrophil survival. ${ }^{21,48}$ The results obtained using the Proteome Profiler (human phospho-MAP kinase array kit) indicated a basal phosphorylation of the serinethreonine kinases GSK(glycogen synthase kinase)-3 $\alpha / \beta$, RSK(ribosomal protein S6 kinase)-1 and Akt in long-lived neutrophils. In contrast, the above kinases were not activated in non-stimulated circulating neutrophils. Significantly, these downstream components of the PI3-kinase pathway are involved in transmission of anti-apoptotic survival messages induced by chemotactic agents in neutrophils. ${ }^{49}$ Thus, the present results suggest a probable role for these kinases in the extended lifespan of long-lived neutrophils.

The phenotype of long-lived neutrophils differs substantially from that of the circulating neutrophils. The surface phenotype of long-lived neutrophils, for instance, is indicative of the acquisition of novel 'non-classic' neutrophil functions. Although still expressing the usual neutrophil cell surface markers CD32, CD18 and CD11b, they acquired new surface proteins, such as HLA-DR and the co-stimulation molecule CD80, which are associated with antigen presentation. We note a similar instance of inflammatory 

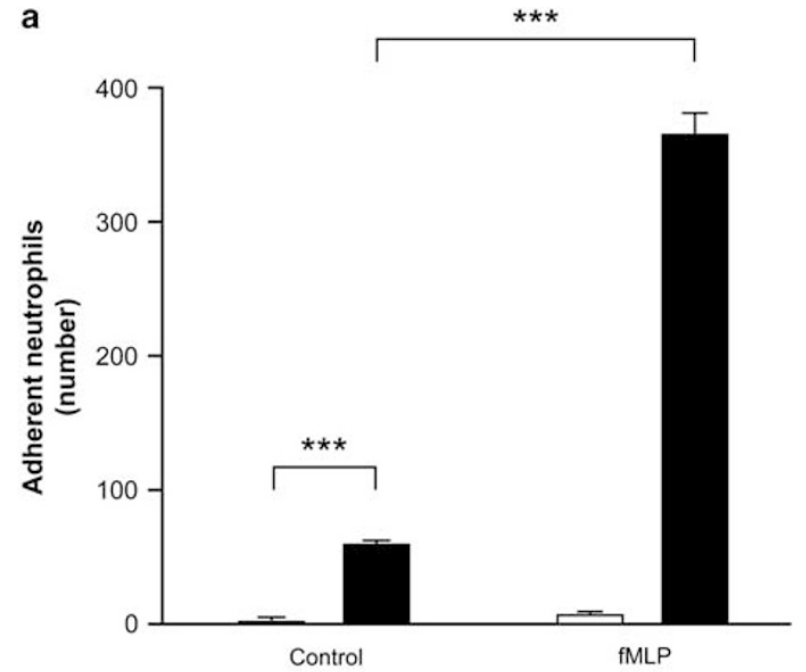

b
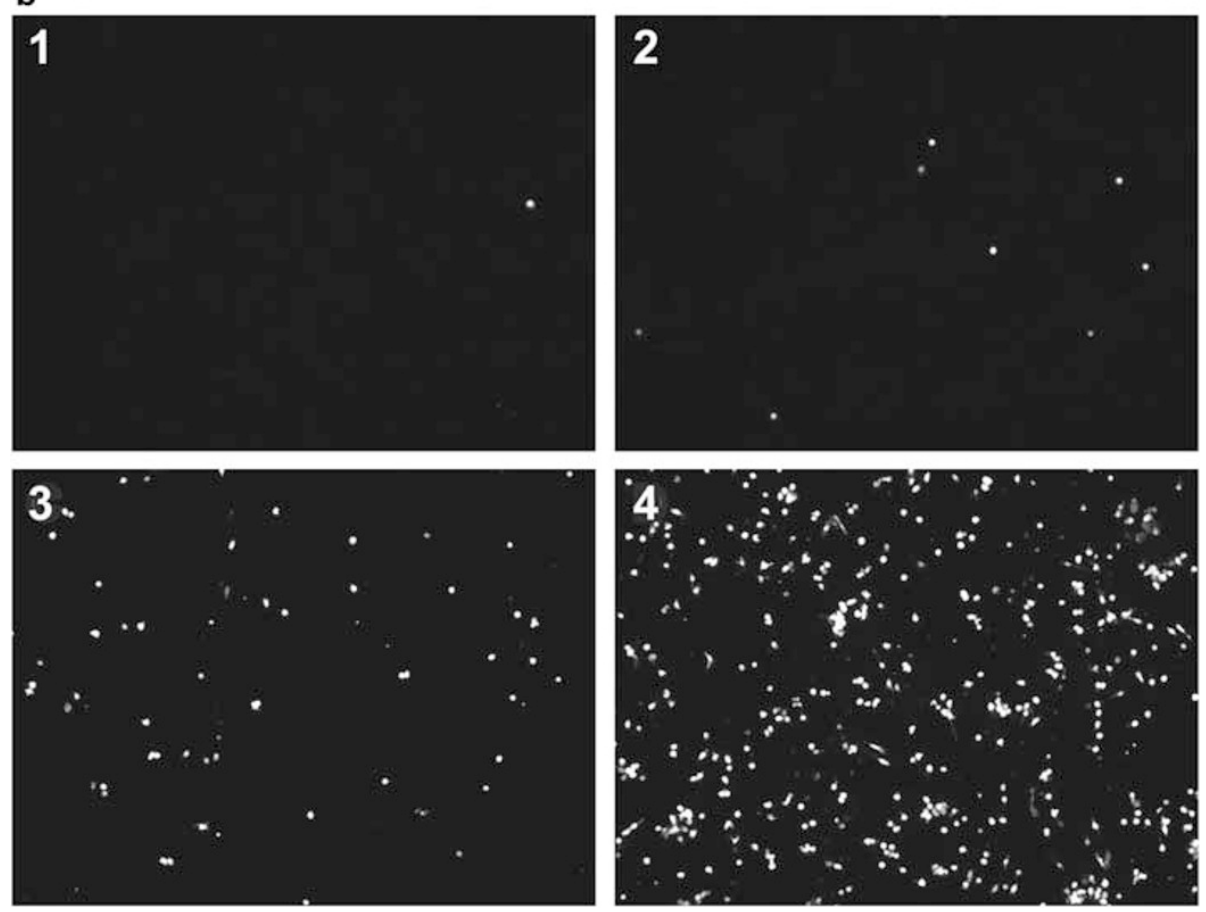

Figure 9 Adhesion of neutrophils to fibroblasts. Freshly isolated neutrophils $(\square)$ and long-lived neutrophils ( $\square$ ) with calcein-AM as tracer were added to confluent monolayers of primary normal synovial fibroblasts in culture in the presence or absence of pre-stimulation with $10^{-7} \mathrm{M}$ fMLP for 5 min at $37^{\circ} \mathrm{C}$. Adhesion was evaluated by fluorescence microscopy (magnification $\times 100$ ). (a) The results are means \pm s.e.m. of adherent cells counted in five separate fields/well. Statistics: Student's paired $t$-test for unstimulated freshly isolated neutrophils vs unstimulated long-lived neutrophils, unstimulated vs fMLP-stimulated long-lived neutrophils $(* * * P<0.001)$. (b) Panels 1 and 2 show adhesion of freshly isolated neutrophils before and after $f M L P$ stimulation; Panels 3 and 4 show adhesion of long-lived neutrophils before and after fMLP stimulation. The results are representative of three different donors.

reprogramming in synovial fluid neutrophils, a percentage of which expressed functional HLA-DR. ${ }^{50}$ Neutrophils from patients with vasculitis and systemic bacterial infections also acquire novel surface receptors and functions, such as expression of CD64, CD14 and neoexpression of HLA-DR and CD83. ${ }^{51,52}$ In addition, we showed that, relative to freshly isolated neutrophils, long-lived neutrophils have increased cell surface ICAM-1, neoexpression of CD49d with concomitant diminution in expression of the traditional neu- trophil adhesion integrins $\beta_{1}$ and $\beta_{2}$. This unique pattern of expression of adhesion molecules might underlie the robust adhesion of this subset of long-lived neutrophils to stromal cells. Neutrophils have, in other respects, a strong capacity to functionally interact with immune cells, fibroblasts, endothelial cells and osteoblasts. ${ }^{53-57}$

What would be the functional correlates of this cytokineinduced reprogramming? We show that long-lived neutrophils have diminished migration to certain chemotactic 

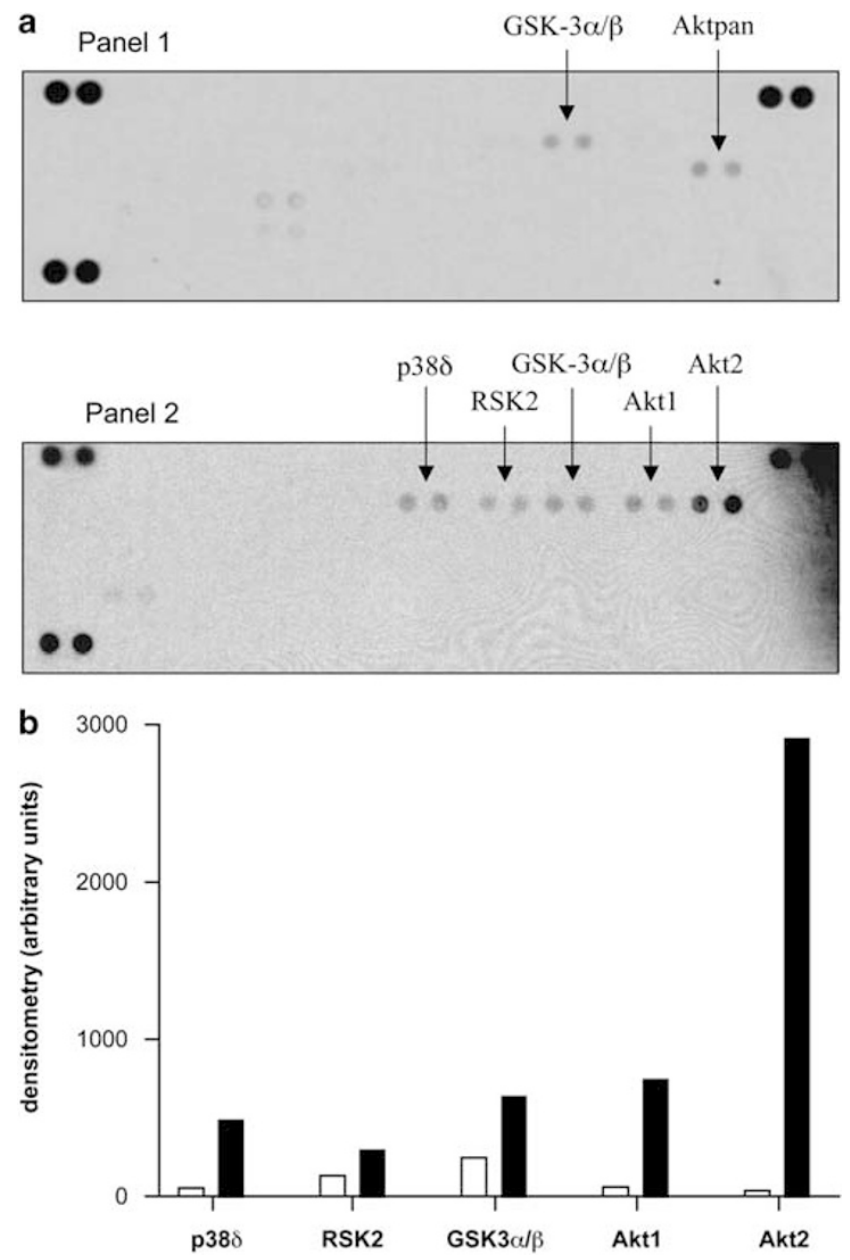

Figure 10 Human phospho-MAPK proteome profile of neutrophils. (a) Equal amounts of cell lysates of freshly isolated neutrophils (Panel 1) and long-lived neutrophils (Panel 2) were deposited on nitrocellulose membranes spotted in duplicate with capture and control antibodies. A cocktail of phospho-site-specific biotinylated antibodies was used to detect phosphorylated kinases. The arrays were exposed to StreptavidinHRP and the ECL detection system before development on X-ray films. Spots were identified by alignment with grid provided in the kit. Arrays shown are representative of three different neutrophil donors. (b) Densitometric analysis of phosphorylation states of serine/threonine kinases in freshly isolated neutrophils ( $\square$ ) and long-lived neutrophils ( $\square$ ). The results are expressed in arbitrary units of densitometry. Data shown are representative of three different donors. GSK, glycogen synthase kinase; RSK, ribosomal protein S6 kinase.

stimuli, phagocytize more particles and release less of destructive enzymes. Moreover, they show a high capacity for cytokine synthesis such as the chemoattractant IL-8, the antagonist of IL-1R and IL- $1 \beta$. The IL-1Ra/IL- 1 ratio is $238 \pm 99$ ( $n=3$ paired donors), and neutrophil IL-1Ra is thus in a range to effectively neutralize IL-1 bioactivity. ${ }^{58}$ As tissue-infiltrated neutrophils are in a cytokine-rich milieu that may potentially change their responsiveness to second signals, we studied the effects of a subsequent stimulation on neutrophils pre-exposed to prolonged incubation with cytokines. They showed a very characteristic profile, particularly evident in $\mathrm{O}_{2}^{-}$production. Responses to fMLP were about five times greater in long-lived neutrophils than in freshly isolated neutrophils. The response to the ionophore A23187 that increases intracellular calcium concentration was, however, diminished whereas response to the PKC activator, PMA, remained unchanged. The above agonists elicit their responses by triggering specific signaling pathways and our results suggest qualitative and quantitative differences in the intracellular mechanisms between these long-lived neutrophils and circulating neutrophils. The phospholipid metabolic pathway leading to leukotriene $\mathrm{B}_{4}$ synthesis also illustrates such differences. Interestingly, a significant amount of the 5-LO localized to the nuclear membrane in long-lived neutrophils in basal conditions, a phenomenon absent in circulating neutrophils. Furthermore, stimulation with fMLP had a much stronger effect on 5-LO translocation to membrane in the long-lived $v s$ circulating neutrophils, a marked difference that might underlie the much greater capacity of the long-lived neutrophils to produce LTs on fMLP stimulation. Notably, instances of altered LT generation were also seen in pathological situations similar to SF neutrophils from patients with RA. ${ }^{59,60}$ However, long-lived neutrophils under fMLP challenge showed a dramatic increase in the $\mathrm{LTA}_{4}$ derived non-enzymatic hydrolysis products. This could suggest that $\mathrm{LTA}_{4}$ from this neutrophil subpopulation is exported and hydrolyzed to the isomers in vitro. This increase of $\mathrm{LTA}_{4}$ production by long-lived neutrophils could be destined for transcellular synthesis of $\mathrm{LTA}_{4}$. This finding would be consistent with the drastic effect of fMLP on the adherence of long-lived neutrophils to fibroblasts, and with the phenotype switch in neutrophil-derived lipid mediators identified during the course of inflammation and its programmed resolution. Long-lived neutrophils could increase their $\mathrm{LTA}_{4}$ biosynthesis without a concomitant increase in the production of $\mathrm{LTA}_{4}$ hydrolase required for $\mathrm{LTB}_{4}$ generation. $\mathrm{LTA}_{4}$ could, thus, be converted into bioactive products other than $\mathrm{LTB}_{4}$, such as lipoxins known to have actions different from those of leukotrienes. Moreover, the local microenvironment of these long-lived neutrophils would dictate the conversion fate of the high amounts of $\mathrm{LTA}_{4}$ generated.

The results presented here might be a specific example of a more generalized phenotype-switching process. Many other groups have shown various cytokine combinations to influence neutrophil surface marker expression differentially, though these studies lacked functional characterization. TNF- $\alpha$ and IFN- $\gamma$ induce the expression of CCR6 and $\mathrm{CD} 83,{ }^{61}$ whereas GM-CSF and IFN- $\gamma$ favor the expression of HLA-DR without concomitant expression of costimulatory molecules. ${ }^{37}$ Functional modulation also suggests underlying transcriptome regulation similar to that seen in infiltrating neutrophils in endotoxin-mediated lung injury and in GM-CSF-stimulated neutrophils. ${ }^{12,13}$

In conclusion, cytokine-induced emergence of neutrophil subsets indicates that neutrophils, far from being terminally 
differentiated cells, should be considered as a versatile longlived entity. A better characterization of different long-lived neutrophils may enable new approaches to target these subpopulations of neutrophils with minimal effects on the immunologically indispensable circulating cells. As evidence accumulates on the role of the neutrophil in disease pathogenesis, further comprehension of the different aspects of neutrophil biology will aid in developing target specific and disease-specific tools.

\section{ACKNOWLEDGEMENTS}

We thank Mrs Andrée-Anne Marceau and Line Bouchard for her excellent technical assistance. This work was supported by a grant from the Canadian Institutes of Health Research.

\section{DISCLOSURE/CONFLICT OF INTEREST}

The authors declare no conflict of interest.

1. Witko-Sarsat V, Rieu P, Descamps-Latscha B, et al. Neutrophils: molecules, functions and pathophysiological aspects. Lab Invest 2000;80:617-653.

2. Chatham WW, Swaim R, Frohsin Jr $\mathrm{H}$, et al. Degradation of human articular cartilage by neutrophils in synovial fluid. Arthritis Rheum 1993;36:51-58.

3. Duan $H$, Koga $T$, Kohda $F$, et al. Interleukin-8-positive neutrophils in psoriasis. J Dermatol Sci 2001;26:119-124.

4. Hermanowicz A, Gibson PR, Jewell DP. The role of phagocytes in inflammatory bowel disease. Clin Sci (Lond) 1985;69:241-249.

5. Mitsuyama K, Toyonaga A, Sasaki E, et al. IL-8 as an important chemoattractant for neutrophils in ulcerative colitis and Crohn's disease. Clin Exp Immunol 1994;96:432-436.

6. Muller KM, Jaunin F, Masouye I, et al. Involvement of granulocytes and the adhesion receptors intercellular adhesion molecule- 1 and lymphocyte function-associated antigen-1 in tissue inflammation induced by Th2-type helper cells. J Invest Dermatol 1995;104:350-354.

7. Raza K, Falciani F, Curnow SJ, et al. Early rheumatoid arthritis is characterized by a distinct and transient synovial fluid cytokine profile of T cell and stromal cell origin. Arthritis Res Ther 2005;7: R784-R795.

8. Brach MA, deVos S, Gruss HJ, et al. Prolongation of survival of human polymorphonuclear neutrophils by granulocyte-macrophage colonystimulating factor is caused by inhibition of programmed cell death. Blood 1992;80:2920-2924.

9. Colotta F, Re F, Polentarutti N, et al. Modulation of granulocyte survival and programmed cell death by cytokines and bacterial products. Blood 1992;80:2012-2020.

10. Francois S, El Benna J, Dang PM, et al. Inhibition of neutrophil apoptosis by TLR agonists in whole blood: involvement of the phosphoinositide 3-kinase/Akt and NF-kappaB signaling pathways, leading to increased levels of Mcl-1, A1, and phosphorylated Bad. J Immunol 2005;174:3633-3642.

11. Kilpatrick LE, Sun $S$, Mackie D, et al. Regulation of TNF mediated antiapoptotic signaling in human neutrophils: role of delta-PKC and ERK1/2. J Leukoc Biol 2006;80:1512-1521.

12. Kobayashi SD, Voyich JM, Whitney AR, et al. Spontaneous neutrophil apoptosis and regulation of cell survival by granulocyte macrophagecolony stimulating factor. J Leukoc Biol 2005;78:1408-1418.

13. Coldren CD, Nick JA, Poch KR, et al. Functional and genomic changes induced by alveolar transmigration in human neutrophils. Am J Physiol Lung Cell Mol Physiol 2006;291:L1267-L1276.

14. Ottonello L, Cutolo M, Frumento G, et al. Synovial fluid from patients with rheumatoid arthritis inhibits neutrophil apoptosis: role of adenosine and proinflammatory cytokines. Rheumatology (Oxford) 2002;41:1249-1260.

15. Raza K, Scheel-Toellner D, Lee CY, et al. Synovial fluid leukocyte apoptosis is inhibited in patients with very early rheumatoid arthritis. Arthritis Res Ther 2006;8:R120.
16. Watson RW, Rotstein OD, Parodo J, et al. Impaired apoptotic death signaling in inflammatory lung neutrophils is associated with decreased expression of interleukin-1 beta converting enzyme family proteases (caspases). Surgery 1997;122:163-171; discussion 171-162.

17. al-Essa LY, Niwa M, Kohno K, et al. Heterogeneity of circulating and exudated polymorphonuclear leukocytes in superoxidegenerating response to cyclic AMP and cyclic AMP-elevating agents. Investigation of the underlying mechanism. Biochem Pharmacol 1995;49:315-322.

18. Puellmann $K$, Kaminski WE, Vogel $M$, et al. A variable immunoreceptor in a subpopulation of human neutrophils. Proc Natl Acad Sci USA 2006;103:14441-14446.

19. Tsuda $Y$, Takahashi $H$, Kobayashi $M$, et al. Three different neutrophil subsets exhibited in mice with different susceptibilities to infection by methicillin-resistant Staphylococcus aureus. Immunity 2004;21: 215-226.

20. Boey $\mathrm{H}$, Rosenbaum R, Castracane J, et al. Interleukin-4 is a neutrophil activator. J Allergy Clin Immunol 1989;83:978-984.

21. Cowburn AS, Deighton J, Walmsley SR, et al. The survival effect of TNFalpha in human neutrophils is mediated via NF-kappa B-dependent IL8 release. Eur J Immunol 2004:34:1733-1743.

22. Deveci $\mathrm{F}$, Muz MH, llhan $\mathrm{N}$, et al. Evaluation of the anti-inflammatory effect of infliximab in a mouse model of acute asthma. Respirology 2008;13:488-497.

23. Schaerli $P$, Britschgi $M$, Keller $M$, et al. Characterization of human $T$ cells that regulate neutrophilic skin inflammation. J Immunol 2004;173:2151-2158.

24. Boyum A. Isolation of mononuclear cells and granulocytes from human blood. Isolation of monuclear cells by one centrifugation, and of granulocytes by combining centrifugation and sedimentation at $1 \mathrm{~g}$. Scand J Clin Lab Invest Suppl 1968;97:77-89.

25. Ren $Y$, Stuart $L$, Lindberg FP, et al. Nonphlogistic clearance of late apoptotic neutrophils by macrophages: efficient phagocytosis independent of beta 2 integrins. J Immunol 2001;166:4743-4750.

26. Laviolette $M$, Bosse $M$, Rocheleau $H$, et al. Comparison of two modified techniques for purifying blood eosinophils. J Immunol Methods 1993;165:253-261.

27. Naccache PH, Grimard $M$, Roberge $C J$, et al. Crystal-induced neutrophil activation. I. Initiation and modulation of calcium mobilization and superoxide production by microcrystals. Arthritis Rheum 1991;34: 333-342.

28. Babior BM, Kipnes RS, Curnutte JT. Biological defense mechanisms. The production by leukocytes of superoxide, a potential bactericidal agent. J Clin Invest 1973;52:741-744.

29. Bradley PP, Christensen RD, Rothstein G. Cellular and extracellular myeloperoxidase in pyogenic inflammation. Blood 1982;60:618-622.

30. Ligeti $E$, Mocsai A. Exocytosis of neutrophil granulocytes. Biochem Pharmacol 1999;57:1209-1214.

31. Krump E, Picard S, Mancini J, et al. Suppression of leukotriene B4 biosynthesis by endogenous adenosine in ligand-activated human neutrophils. J Exp Med 1997;186:1401-1406.

32. Borgeat $\mathrm{P}$, Picard $\mathrm{S}$, Vallerand $\mathrm{P}$, et al. Automated on-line extraction and profiling of lipoxygenase products of arachidonic acid by high-performance liquid chromatography. Methods Enzymol 1990;187:98-116.

33. Surette ME, Chilton FH. The distribution and metabolism of arachidonate-containing phospholipids in cellular nuclei. Biochem J 1998;330(Pt 2):915-921.

34. Butcher SK, Chahal H, Nayak L, et al. Senescence in innate immune responses: reduced neutrophil phagocytic capacity and CD16 expression in elderly humans. J Leukoc Biol 2001;70:881-886.

35. Cowland JB, Borregaard N. Isolation of neutrophil precursors from bone marrow for biochemical and transcriptional analysis. J Immunol Methods 1999;232:191-200.

36. Ward C, Wong TH, Murray J, et al. Induction of human neutrophil apoptosis by nitric oxide donors: evidence for a caspase-dependent, cyclic-GMP-independent, mechanism. Biochem Pharmacol 2000;59:305-314.

37. Yamashiro S, Kamohara $\mathrm{H}$, Wang JM, et al. Phenotypic and functional change of cytokine-activated neutrophils: inflammatory neutrophils are heterogeneous and enhance adaptive immune responses. J Leukoc Biol 2001;69:698-704. 
38. McColl SR, Beauseigle D, Gilbert C, et al. Priming of the human neutrophil respiratory burst by granulocyte-macrophage colonystimulating factor and tumor necrosis factor-alpha involves regulation at a post-cell surface receptor level. Enhancement of the effect of agents which directly activate $G$ proteins. J Immunol 1990;145:3047-3053.

39. Sugawara T, Miyamoto M, Takayama S, et al. Separation of neutrophils from blood in human and laboratory animals and comparison of the chemotaxis. J Pharmacol Toxicol Methods 1995;33:91-100.

40. Byrum RS, Goulet JL, Snouwaert JN, et al. Determination of the contribution of cysteinyl leukotrienes and leukotriene B4 in acute inflammatory responses using 5-lipoxygenase- and leukotriene A4 hydrolase-deficient mice. J Immunol 1999;163:6810-6819.

41. Samuelsson B. Leukotrienes: mediators of immediate hypersensitivity reactions and inflammation. Science 1983;220:568-575.

42. McDonald PP, McColl SR, Naccache PH, et al. Studies on the activation of human neutrophil 5-lipoxygenase induced by natural agonists and Ca2+ ionophore A23187. Biochem J 1991;280(Pt 2):379-385.

43. Cassatella MA. Neutrophil-derived proteins: selling cytokines by the pound. Adv Immunol 1999;73:369-509.

44. Giuliani AL, Spisani S, Cavalletti T, et al. Fibroblasts increase adhesion to neutrophils after stimulation with phorbol ester and cytokines. Cell Immunol 1993;149:208-222.

45. Rezzonico R, Burger D, Dayer JM. Direct contact between $T$ lymphocytes and human dermal fibroblasts or synoviocytes down-regulates types I and III collagen production via cell-associated cytokines. J Biol Chem 1998;273:18720-18728.

46. Shock A, Laurent GJ. Adhesive interactions between fibroblasts and polymorphonuclear neutrophils in vitro. Eur J Cell Biol 1991;54:211-216.

47. Pap M, Cooper GM. Role of glycogen synthase kinase-3 in the phosphatidylinositol 3-Kinase/Akt cell survival pathway. J Biol Chem 1998;273:19929-19932.

48. Nijhuis E, Lammers JW, Koenderman L, et al. Src kinases regulate PKB activation and modulate cytokine and chemoattractant-controlled neutrophil functioning. J Leukoc Biol 2002;71:115-124.

49. De Mesquita DD, Zhan Q, Crossley L, et al. p90-RSK and Akt may promote rapid phosphorylation/inactivation of glycogen synthase kinase 3 in chemoattractant-stimulated neutrophils. FEBS Lett 2001;502:84-88.
50. Cross A, Bucknall RC, Cassatella MA, et al. Synovial fluid neutrophils transcribe and express class II major histocompatibility complex molecules in rheumatoid arthritis. Arthritis Rheum 2003:48: 2796-2806.

51. Iking-Konert C, Ostendorf B, Sander O, et al. Transdifferentiation of polymorphonuclear neutrophils to dendritic-like cells at the site of inflammation in rheumatoid arthritis: evidence for activation by T cells. Ann Rheum Dis 2005;64:1436-1442.

52. Wagner $C$, Pioch $M$, Meyer $C$, et al. Differentiation of polymorphonuclear neutrophils in patients with systemic infections and chronic inflammatory diseases: evidence of prolonged life span and de novo synthesis of fibronectin. J Mol Med 2000;78: 337-345.

53. Bouchard L, Naccache PH, Poubelle PE. Promotion of neutrophil adherence to human osteoblasts by microcrystals and f-Met-Leu-Phe. Biochem Biophys Res Commun 2002;296:759-764.

54. Filer A, Parsonage G, Smith E, et al. Differential survival of leukocyte subsets mediated by synovial, bone marrow, and skin fibroblasts: site-specific versus activation-dependent survival of T cells and neutrophils. Arthritis Rheum 2006;54:2096-2108.

55. Ling CJ, Owen Jr WF, Austen KF. Human fibroblasts maintain the viability and augment the functional response of human neutrophils in culture. J Clin Invest 1990;85:601-604.

56. van Gisbergen KP, Sanchez-Hernandez M, Geijtenbeek TB, et al. Neutrophils mediate immune modulation of dendritic cells through glycosylation-dependent interactions between Mac-1 and DC-SIGN. J Exp Med 2005;201:1281-1292.

57. Zhang JH, Ferrante A, Arrigo AP, et al. Neutrophil stimulation and priming by direct contact with activated human $\mathrm{T}$ lymphocytes. J Immunol 1992;148:177-181.

58. Dinarello CA. Interleukin-1 and interleukin-1 antagonism. Blood 1991;77:1627-1652.

59. Langholz $\mathrm{E}$, Nielsen $\mathrm{OH}$, Ahnfelt-Ronne I, et al. Arachidonic acid metabolism in neutrophil granulocytes obtained from synovial fluid in rheumatoid arthritis. Scand J Rheumatol 1990;19:387-391.

60. Poubelle PE, Bourgoin S, McColl SR, et al. Altered formation of leukotriene B4 in vitro by synovial fluid neutrophils in rheumatoid arthritis. J Rheumatol 1989;16:280-284.

61. Yamashiro S, Wang JM, Yang D, et al. Expression of CCR6 and CD83 by cytokine-activated human neutrophils. Blood 2000;96:3958-3963. 